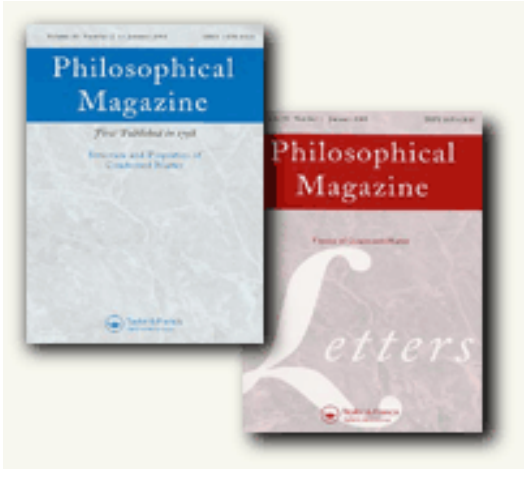

\title{
Nanostructured silicon and its application to solar cells, position sensors and thin film transistors
}

\begin{tabular}{|c|c|}
\hline Journal: & Philosophical Magazine \& Philosophical Magazine Letters \\
\hline Manuscript ID: & TPHM-08-Oct-0362.R3 \\
\hline Journal Selection: & Philosophical Magazine \\
\hline $\begin{array}{l}\text { Date Submitted by the } \\
\text { Author: }\end{array}$ & 20-Feb-2009 \\
\hline Complete List of Authors: & $\begin{array}{l}\text { Martins, Rodrigo; Universidade Nova de Lisboa, Dept. de Ciencia } \\
\text { dos Materiais da Faculdade de Ciencias e Technologia; Faculty of } \\
\text { Science and Technology, Materials Science Department } \\
\text { Raniero, Leandro; Universidade do Vale do Paraiba, Instituto de } \\
\text { Pesquisa e Desenvolvimento } \\
\text { Pereira, Luis; Universidade Nova de Lisboa, Dept. de Ciencia dos } \\
\text { Materiais da Faculdade de Ciencias e Technologia } \\
\text { Costa, Daniel; Universidade Nova de Lisboa, Dept. de Ciencia dos } \\
\text { Materiais da Faculdade de Ciencias e Technologia } \\
\text { Aguas, Hugo; Universidade Nova de Lisboa, Dept. de Ciencia dos } \\
\text { Materiais da Faculdade de Ciencias e Technologia } \\
\text { Pereira, Sonia; Universidade Nova de Lisboa, Dept. de Ciencia dos } \\
\text { Materiais da Faculdade de Ciencias e Technologia } \\
\text { Silva, Leonardo; Universidade Nova de Lisboa, Dept. de Ciencia dos } \\
\text { Materiais da Faculdade de Ciencias e Technologia } \\
\text { Ferreira, Isabel; Universidade Nova de Lisboa, Dept. de Ciencia dos } \\
\text { Materiais da Faculdade de Ciencias e Technologia } \\
\text { Fortunato, Elvira; Universidade Nova de Lisboa, Dept. de Ciencia } \\
\text { dos Materiais da Faculdade de Ciencias e Technologia } \\
\text { Goncalves, Alexandra; Universidade Nova de Lisboa }\end{array}$ \\
\hline Keywords: & $\begin{array}{l}\text { a-Si:H, image processing, nanostructures, position-sensitive } \\
\text { detectors, thin-film solar cells, thin-film transistors }\end{array}$ \\
\hline Keywords (user supplied): & a-Si:H, image processing, nanostructures \\
\hline
\end{tabular}




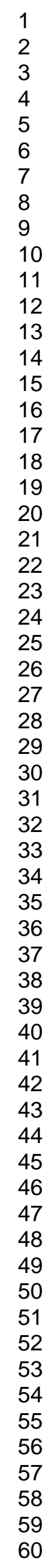

5) ScholaroNE"

http://mc.manuscriptcentral.com/pm-pml 


\title{
Nanostructured silicon and its application to solar cells, position sensors and thin film transistors
}

\author{
R. Martins ${ }^{1}$, L. Raniero ${ }^{2}$, L. Pereira ${ }^{1}$, D. $\operatorname{Costa}^{1+}$, H. Águas ${ }^{1}$, S. Pereira ${ }^{1}$, L. Silva ${ }^{1}$, A. \\ Gonçalves $^{1}$, I. Ferreira ${ }^{1}$, E. Fortunato ${ }^{1}$ \\ ${ }^{1}$ Materials Science Department, CENIMAT/I3N, Faculty of Sciences and Technology of New \\ University of Lisbon and CEMOP/UNINOVA, Campus de Caparica, 2829-516 Caparica, \\ Portugal \\ ${ }^{2}$ Universidade do Vale do Paraíba, Instituto de Pesquisa e Desenvolvimento, Av. Shishima \\ Hifumi, 2911 - Urbanova, São José dos Campos - SP, Brazil
}

This paper reports the performances of small area solar cells, 128 linear integrated position sensitive detector arrays and thin film transistors based on nanostructured silicon thin films produced by plasma enhanced chemical vapour deposition technique, close to the onset of dusty plasma conditions, within the transition region from amorphous to microcrystalline. The small area solar cells produced in a modified single chamber reactor exhibited very good electrical characteristics, with a conversion efficiency exceeding $9 \%$. The 128 integrated position sensitive detector arrays, based on similar pin structure, allow real time 3D object imaging with a resolution higher than $90 \mathrm{lp} / \mathrm{mm}$. The thin film transistors produced exhibited field effect mobility of $2.47 \mathrm{~cm}^{2} \mathrm{~V}^{-1} \mathrm{~s}^{-1}$, threshold voltage of $2 \mathrm{~V}$, on/off ratio larger than $10^{7}$ and sub-threshold slopes of $0.32 \mathrm{~V} /$ decade, which are amongst the best results reported for this type of device.

Keywords: nanostructured silicon; thin film devices; position sensitive detectors, TFTs, solar cells

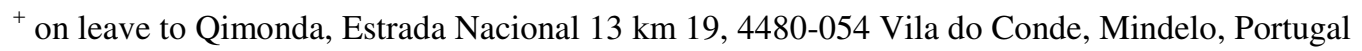




\section{Introduction}

Amorphous silicon (a-Si:H) has been studied for many years [1-3] with a particular emphasis on optoelectronic devices since the demonstration of doping effect by Spear [4]. This material has been intensively studied worldwide involving thousands of researchers and the work of Spear [5, 6] and LeComber [7-9], among others, have been central references. To these studies we have to add the earlier work of Madan et al. [10] in determining the density of localized states that not only supported the development of high grade electronic quality undoped amorphous silicon for device applications, but also was the precursor in the use of amorphous silicon in field effect transistors [11]. Since then the main bottleneck has been the inherent light degradation of a-Si:H [12] and the low carrier mobility which prevents even larger application potential of the material. To overcome the carrier mobility limitation, several authors proposed the production of new silicon alloys [13] or structured ordered thin silicon such as microcrystalline [14-16], polymorphous [17] or protocrystalline [18] silicon. As far as devices are concerned, the main driving force has been its use in solar cells [19], field effect transistors/thin film transistors [20] and sensors [21-25]. Other possible applications have also been tried such as switching memories [26], tunnelling based devices [27], large area position sensitive detectors, (psd) [28, 29] or in biosensors [30, 31].

It seems that the degradation is due to the metastabillity in a-Si:H and closely related to the amorphous network nature and the vast amount of hydrogen atoms within the films. Therefore in order to improve stability and electronic performance, the microstructure must be improved. To reach this goal we produced hydrogenated diphasic nanostructured silicon thin films close to the onset of dusty plasma conditions, within the amorphous to microcrystalline transition region, using high hydrogen dilution conditions [32-36].

In honour of Professor Walter Spear and his strong contribution to the field of amorphous silicon, related alloys and their integration into devices, we present here the results concerning the process conditions used to produce nanostructured hydrogenated silicon (nsSi:H) and its application in solar cells, psd integrated arrays $[37,38]$ and TFT's. The psd 128 integrated array is presented for the first time and fully integrated into a linear camera that allows for real time 3D inspection imaging. Concerning the TFT, the aim is to show that a high performance device can be produced with the material developed as well as to prove that other materials, other than silicon dioxide or silicon nitride, [39] can be successfully used as the dielectrics. 


\section{Experimental details}

\subsection{Material deposition}

The nanostructured thin films were deposited by plasma enhanced chemical vapour deposition (PECVD) at 27.12 MHz, using a single chamber as described elsewhere [34, 40]. The main features of these types of films when compared to the amorphous silicon are the improvement of the short range order and a particular signature given by the hydrogen exodiffusion data (there is a characteristic peak, absent in the amorphous silicon, shifted to high temperatures, when compared to the microcrystalline silicon). Also noticeable is the absence of the usual high hydrogen content measured by infrared spectroscopy that is considered one of the polymorphous finger prints, [14] and the absence of a distinct phase with a low hydrogen concentration occurring during the crystal growth, which evolves into a microcrystalline form (the so-called protocrystalline [15]) [41].

The deposition pressure $(\mathrm{p})$ and the substrate temperature $\left(\mathrm{T}_{\mathrm{s}}\right)$ were fixed at $187 \mathrm{~Pa}$ and $473 \mathrm{~K}$, respectively. The influence of silane concentration $\left[\mathrm{d}_{\mathrm{r}}=\mathrm{SiH}_{4} /\left(\mathrm{SiH}_{4}+\mathrm{H}_{2}\right)\right.$ and the role of power density $\left(\mathrm{P}_{\mathrm{d}}\right)$ on the films' properties were studied on the range from 1 to $9 \%$, and from 63 to $383 \mathrm{~mW} / \mathrm{cm}^{2}$, respectively. The $\mathrm{d}_{\mathrm{r}}$ was varied by increasing the silane flow in the mixture, from 1 to $9 \mathrm{sccm}$, keeping the hydrogen flow constant $(100 \mathrm{sccm})$.

The films deposited were studied by Micro-Raman Spectroscopy and exodiffusion measurements. The exodiffusion data allow the determination of the exodiffusion hydrogen activation energy for the set of films produced, which was deduced from the relation between the heating rate $(\phi)$ and the peak temperature $\left(\mathrm{T}_{\mathrm{m}}\right)$ given by equation 1 [42].

$\frac{E_{a} \phi}{R T^{2}}=A e^{\left(\frac{-E_{a}}{R T}\right)}$

where $\mathrm{A}$ is the reaction constant, $\mathrm{R}$ is the gas constant $(8.31 \mathrm{~J} / \mathrm{mol} . \mathrm{K}), \mathrm{T}$ is the absolute temperature and $\mathrm{E}_{\mathrm{a}}$ is the activation energy for the evolution process. 
Taking logarithms on both sides of equation 1 and differentiating it with respect to $1 / \mathrm{T}_{\mathrm{m}}$ yields [43]:

$\ln \left(\frac{\phi}{T_{m}^{2}}\right) /\left(1 / T_{m}\right)=\frac{E_{a}}{R}$

From the slope of a $\ln \left(\phi / \mathrm{T}_{\mathrm{m}}{ }^{2}\right)$ versus $\left(1 / \mathrm{T}_{\mathrm{m}}\right)$ plot the $\mathrm{E}_{\mathrm{a}}$ was calculated using the Kissinger's method [44] which has been used to determine the activation energy of solid state reactions, through the method of differential thermal analysis. In this method the dominant factor controlling the shape and position of the differential thermal analysis peak is the nature of the reaction itself. The heating rate was varied between 3 to $10 \mathrm{~K} /$ minutes.

\subsection{Solar cells deposition}

The solar cell with a p-doped layer/buffer1/buffer2/i-ns-Si:H layer/ n-doped/Ag/Al structure was deposited on Gallium Zinc Oxide (GZO) coated glass substrate, as described elsewhere [45], using the material deposition conditions defined in section 2.1. The two buffer layers are used to adjust the mismatch in the optical band gap between the p- $(1.94 \mathrm{eV})$ and i$(1.82 \mathrm{eV})$ layers. The band gap of buffer $_{1}$ is $1.88 \mathrm{eV}$ and that of buffer $_{2}$ is $1.84 \mathrm{eV}$. Additionally, the buffer layers are efficient in controlling the diffusion between the dopants of the p- and i- layers [46-48]. The back contact consists of a thin $\mathrm{Ag}$ layer $(\approx 30 \mathrm{~nm})$ used to improve the light reflectance, followed by an Al layer $(\approx 170 \mathrm{~nm})$ with an electrode area of $0.07 \mathrm{~cm}^{2}$ [49]. Table 1 summarizes the characteristics of the different layers as well as the gas mixtures used. the silicon structure was removed by dry etching technique in order to avoid interference of the current collected in the vicinity surrounding the contact [50]. The study of these devices also served to establish the optimised process conditions for producing the integrated psd arrays. The solar cell performance was measured using a sun simulator under AM1.5 illumination conditions. 


\subsection{Linear Integrated psd Arrays Fabrication and Characterization}

The linear integrated array and consisted of 128 psd's configured as a nip structure processed using similar conditions to the ones described for solar cells, with the exception that the intrinsic layer has a thickness above $0.8 \mu \mathrm{m}$. Details concerning the fabrication steps of the psd arrays are given in previous papers [51]. The device linearity versus incident light frequency measurements were taken in the photoconductive mode $[37,51,52]$, where the back metal contact was grounded or reverse biased at $-1 \mathrm{~V}$ and the photocurrents detected at the pad electrodes located on the device edges (see Figure 1). The devices are mounted over a collecting Printed Circuit Board (PCB) unit that contains the controller unit, the analogical/digital (A/D) converter and the MX4 microprocessors, whose schematic is depicted in Figure 2. The functional characteristics of this 128 psd integrated array are depicted in Table 2. The PCB board is connected to the PC via an acquisition data board from National Instruments (NI 6031E). The detection system used to obtain a 3D image directly out of the integrated psd array is depicted in Figure 2, and the camera performance is shown in Table 3. The light source is a diode laser $(670 \mathrm{~nm}, 5 \mathrm{~mW})$, that generates a line focused by a lens towards the surface to be inspected. The linear movement of the device was achieved using an automated control table (Parker-Hannifin M106061S 5M) with a spatial resolution better than $5 \mu \mathrm{m} /$ turn. All the experimental data were gathered using custom-developed software for data acquisition and control.

The main properties of the layers that constitute the devices such as thickness, conductivity and optical gap are the same used to process the solar cells described in section 2.2 and referred in Table 1. 


\subsection{Thin Film Transistor Fabrication and Characterization}

For thin film transistors processing the substrate is located in the dark region of the plasma, underneath a grounded metal grid. By not exposing the growth surface directly to the plasma we avoided the high ion bombardment at the silicon growth surface leading to a less defective surface and highly compact films.

The TFT's were produced using different dielectric layers in a bottom gate configuration, as depicted in Figure 3. The materials used as dielectric were a multilayer of aluminium oxide and titanium oxide, known as ATO; silicon oxide $\left(\mathrm{SiO}_{2}\right)$ and hafnium oxide $\left(\mathrm{HfO}_{2}\right)$ [53]. In the first case, the dielectric was deposited by Atomic Layer deposition (ALD) over indium tin oxide (ITO) that acts as gate electrode. The substrate (glass)/ITO/ATO stack was supplied by Plannar Systems Inc. The $\mathrm{SiO}_{2}$ was obtained by thermal oxidation of highly doped p-type silicon that was metalized on the back surface to form the gate electrode. The $\mathrm{HfO}_{2}$ was deposited by r.f. sputtering over the gate electrode (sputtered indium zinc oxide IZO). Both layers (dielectric and gate electrode) were patterned by lift-off lithography.

The deposition of the ns-Si:H channel layer with $120 \mathrm{~nm}$ thickness was done by PECVD at $200^{\circ} \mathrm{C}$, with a power density of $128 \mathrm{mWcm}^{-2}$, at $27.12 \mathrm{MHz}$, following similar procedures as the ones described in section 2.1, with an aim to obtain nanostructured silicon films (ns-Si:H). The deposition pressure selected was $186 \mathrm{~Pa}$ and the total gas flow $105 \mathrm{sccm}$ with $d_{r} \cong 5 \%$. The source and drain n-type a-Si:H was deposited right after ns-Si:H, without breaking vacuum, also at $200^{\circ} \mathrm{C}$. In this case the power density was $35 \mathrm{mWcm}-2$, using the same 27.12 MHz generator, while the pressure and gas flow $\left(\mathrm{PH}_{3} / \mathrm{SiH}_{4} / \mathrm{H}_{2} / \mathrm{He}\right.$ mixture) were $86 \mathrm{~Pa}(0.65$ torr $)$ and $10 \mathrm{sccm}$, respectively. The growth rate changes from about 10$12 \mathrm{~nm} / \mathrm{min}$ to $6-8 \mathrm{~nm} / \mathrm{min}$ for films grown with or without the grid, respectively. An Al layer $200 \mathrm{~nm}$ thick was evaporated on top of the n-type silicon. The source and drain electrodes were then patterned by photolithography and wet etching using a $\mathrm{H}_{2} \mathrm{PO}_{4}: \mathrm{HNO}_{3}: \mathrm{H}_{2} \mathrm{O}$ solution. 
This metal layer serves as a mask for the n-type silicon etching by Reactive Ion Etching (RIE). The etching time was accurately monitored, to allow for the removal of just the doped layer deposited over the channel layer. The devices were terminated by patterning the channel layer also by photolithography and RIE. In order to enhance the device performance annealing at $200^{\circ} \mathrm{C}$ in a forming gas $\left(95 \% \mathrm{~N}_{2}-5 \% \mathrm{H}_{2}\right)$ atmosphere was performed. The electrical characterization of the TFT was performed using an Agilent 4155C semiconductor analyzer connected to a Microprober Cascade M150, installed inside a dark box.

\section{Results}

\subsection{Processed materials}

Figure 4 shows typical micro-Raman results of the nanostructured films produced (dotted line) and reference data spectra concerning amorphous (dashed line) and microcrystalline (solid line) silicon thin films. The peak shift observed (from $\sim 480 \mathrm{~cm}^{-1}$ to $\sim 485 \mathrm{~cm}^{-1}$ ) is also seen in polymorphous films and it is attributed to the improvement of the structural order at the nanoscale level $[32,54]$.

The hydrogen exodiffusion spectra as a function of temperature are shown in Figure 5. Figure 6 summarizes all the plasma conditions that lead to the production of materials with different type of structures (from amorphous to microcrystalline) as a function of $P_{d}$ and $d_{r}$ used. There we can see the different process conditions that lead to the production of silicon thin films where the amorphous or microcrystalline phases clearly dominate. In-between we can see the transition region, where both phases may exist: close to the microcrystalline phase the predominant structure is dominated by the existence of nanocrystals while close to the amorphous region we may still have a dominant amorphous phase but with a highly improved short range order. 


\subsection{Device results}

\subsubsection{Solar cells}

Figure 8a) shows the cross section of the solar cell. The image reveals a highly compact structure, where we note the typical dense columnar structure of the polycrystalline GZO, exhibiting a bulk resistivity of $2.5 \times 10^{-4} \Omega-\mathrm{cm}$, a mobility close to $20 \mathrm{~cm}^{2} \mathrm{~V}^{-1} \mathrm{~s}^{-1}$ and a transmittance in the visible range above $82 \%$ for a film thickness of about $1.35 \mu \mathrm{m}$ [55-57]. Besides that the GZO films clearly sustain the plasma process as observed when analyzing different types of TCO after sustain an intense hydrogen plasma by $600 \mathrm{~s}$ [58], not suffering any chemical or physical degradation. Near the glass/GZO interface small grains are observed. On the other hand a highly compact structure near the surface makes it impossible to distinguish between grain boundaries, defects or voids.

The image also reveals a well compacted and dense pin structure, where no large crystallites or grains can be seen. That is, we are in the presence of an almost amorphous film where the short range order has been improved, in spite of the hydrogen content of these films [35]. 
Figures $8 \mathrm{~b}$ ) and $8 \mathrm{c}$ ) show the $\mathrm{J}-\mathrm{V}$ characteristics and quantum efficiency curves for the produced small area solar cells.

\subsubsection{Integrated psd arrays}

In Table 3 we present the characteristics of the 128 integrated arrays produced. Figure 9 shows the results of the spatial resolution determined in 1D psd element of the array, using spatial steps down to a minimum of $0.25 \mu \mathrm{m}$ allowed by the measuring system, and a focus light of $50 \mathrm{~mW} / \mathrm{cm}^{2}$. As observed both measurements are linear but the proximity of the points in the $0.25 \mu \mathrm{m}$ measurement causes the current to oscillate in a way that one value of current can correspond to two or three positions, which would lead to an inaccuracy in its position. That is, the random distribution of currents measured to determine a clear position is out of the admissible error window. In spite of this, a still linear behaviour can be foreseen. This means that the minimum resolution of the sensor is higher than $0.25 \mu \mathrm{m}$. With the $1 \mu \mathrm{m}$ step measurements the case of a current value corresponding to two or more positions does not occur, so with $1 \mu \mathrm{m}$ step it is already possible to determine a position with an accuracy of $\pm 0.5 \mu \mathrm{m}$.

\subsubsection{Thin film transistor}

Figure 10a) shows the transfer characteristics and the transconductance $\left(g_{m}\right)$ variation with the gate voltage $\left(\mathrm{V}_{\mathrm{GS}}\right)$, for the set of TFTs analysed using different dielectrics. The typical electrical parameters extracted from the transfer characteristics such as the field effect mobility $\left(\mu_{F E}\right)$, threshold voltage $\left(V_{T}\right)$, on/off ratio $\left(I_{o n} / I_{o f f}\right)$ and sub-threshold slope $(S)$ are shown in Table 4. In Figure 10b the transfer characteristics of the TFT produced using different channel dimensions, on linear $\left(\mathrm{V}_{\mathrm{DS}}=1 \mathrm{~V}\right)$ and saturation regimes $\left(\mathrm{V}_{\mathrm{DS}}=10 \mathrm{~V}\right)$, for nsSi:H TFT with different channel dimensions integrating $\mathrm{SiO}_{2}$ as dielectric are shown. In 


\section{Discussion}

\subsection{Materials properties}

The spectra in Figure 4 show the three main types of materials produced, which are: 1) amorphous films, represented by a single Gaussian peak centred around $480 \mathrm{~cm}^{-1}$ [59]; 2) the microcrystalline films, with a band close to the sharp peak around $516 \mathrm{~cm}^{-1}$; 3) the nanostructured films, represented by an improved short range order, where some nanocrystals exist $(<2 \%)$. This is conjectured by a slight shift of the amorphous peak towards higher wavenumbers together with a slight narrowing of the full width at half maximum (FWHM). This shift towards higher wavenumbers can be attributed to the presence of nanocrystals randomly distributed in the the film or to the improvement of the short range order. The presence of such nanocrystals (of small size, $<10 \mathrm{~nm}$ ) and of short range order clusters can lead to an internal film stress that are responsible for the shift observed [59].

The exodiffusion data are shown in Figure 5 and together with the illustrations helps to understand the characteristics of the structure of the materials developed. The films with different structures have different ways to release the bonded hydrogen, as a function of the sample's temperature. The first highest peak (at low temperature - LT) corresponds to hydrogen exodiffusion from microcrystalline silicon, due to loosely bonded hydrogen at the grain boundaries, while the HT peak of the same spectrum corresponds to hydrogen tightly bonded to silicon in the remaining amorphous phase. 
With respect to the amorphous silicon film, in the exodiffusion spectrum (dash line) the LT peak represents the weak $\mathrm{SiH}_{2} / \mathrm{SiH}_{3}$ bonds and cluster adsorbed by physisorbtion originated from van der Waals interaction. The illustration (b) depicted in Figure 5 shows a nanostructured film, which shares some similarity with a microcrystalline structure since we also have the presence of some grain boundaries, but now with a large fraction of amorphous tissue. This explanation is in agreement with the collected exodiffusion spectrum where a third spectrum corresponding to films produced in the so-called transition region, where the present films have been deposited, is shown. In this spectrum the LT peak is shifted towards $703 \mathrm{~K}$ (about $60 \mathrm{~K}$ above the previous LT peak). Its position peak can be explained by the presence of a mixed phase material (disorder/short range order or disorder/nano-order), where tightly bonded hydrogen prevalent in the amorphous tissue with a combination of hydrogen in possible cavities or in the boundaries of nano-grains. These data, together with the role of hydrogen dilution and $\mathrm{P}_{\mathrm{d}}$ used, leads to the schematic shown in Figure 6, where a small "window" corresponding to films deposited on the transition region is defined. The transition region where nanostructured films can be processed depends on the reactor configuration and temperature uniformity on the deposition chamber $[32,60,61]$.

Indeed the interaction between atomic hydrogen and the surface during the deposition process markedly influences the type of structured film obtained [62]. As observed in Figure 7, the hydrogen evolution in films produced in the transition region reveals that they have a compositional structure different from that of conventional amorphous silicon. In order to compare the films' properties, the exodiffusion hydrogen activation energy was calculated using the Kissinger's method [44]. The values recorded for the nanostructured films at LT and HT peaks are shown in Figure 11, and the data fitted by equation 2 . The $\mathrm{E}_{\mathrm{a}}$ data reported in the literature for amorphous silicon for the LT and HT peaks are $79 \mathrm{KJ} / \mathrm{mol}$ and $112 \mathrm{KJ} / \mathrm{mol}$, respectively [42]. On the other hand, the $E_{a}$ data obtained for the nanostructured films for the 


\subsection{Solar cells}

The analysis of the plots shown in Figure 8 for single junction solar cells based on nsSi:H films leads to a fill factor of 0.67 , an open circuit voltage of $0.94 \mathrm{~V}$ and a short circuit current density of $14.48 \mathrm{~mA} / \mathrm{cm}^{2}$, leading to a conversion efficiency of $9.12 \%$.

The high current density and good value obtained for the quantum efficiency are mainly attributed to the quality of the i-layer and to the p/i interface that does not annihilate the photocarriers generated, and the use of GZO as the front contact contributes since it is not degraded by the hydrogen plasma during the deposition of the p-layer [45-47]. This is probably due to the stability of the GZO leading to improved transmittance at the blue region of the spectrum. The high value of open circuit voltage is related to the wide band gap and high work function of GZO (respectively above $3.4 \mathrm{eV}$ and $4.95 \mathrm{~V}$ ), which leads to an enhancement of the band offsets between the p-type silicon front layer and the transparent conductive oxide layer used [63]. This analysis is supported by data achieved on similar solar cells where the only change in fabrication was to use the conventional amorphous i-layer, keeping all other constituent layers the same. The data achieved under these conditions lead to short circuit current, fill factor and open circuit voltage of $13 \mathrm{mAcm}^{-2}, 0.62$ and $0.92 \mathrm{~V}$ respectively, leading to overall device efficiency of $7.4 \%$. After continuous AM1.5 
illumination for $250 \mathrm{~h}$, we notice that the overall efficiency of the solar cells stabilizes to a value around $8.50 \%$, showing that these devices are more stable than a-Si:H based solar cells where a strong device degradation, sometimes exceeding $20 \%$ has been reported [46]. These data cannot be compared with industry data where the devices are differently processed, as are the recent reported data from MVSystems and United Solar for instance [64-69]. The aim is to prove the consistency of the laboratory results [63] and the integration of these nanostructured silicon thin films in device structure such as solar cells, thin film position sensitive detectors and thin film transistors.

\subsection{Integrated psd arrays}

\subsubsection{Working principles}

The operation principle of the psd array is that an image line projected in the array induces photocurrents $\left(I_{p h 1}\right.$ and $\left.I_{p h 2}\right)$ or lateral photo voltages $\left(\Delta V=V_{l^{-}} V_{2}\right)$ in the illuminated elements (see Figure 12). Then all elements are scanned to determine the position of the image line. In this case the angle of incidence that the laser line makes with the surface to be inspected should be such that allows its detection along the length of the detector. That is, the maximum active length $d_{d}$ of each element of the array has to be such that:

$$
d_{0}(\max ) \geq \frac{d_{d}(\max )}{\cos \phi}
$$

where $d_{0}$ is the distance between the sensor and the surface to be scanned $[70,71]$. Each element $\Delta I_{p h}$ has an uncertainty related to the noise $(n)$ and so, the measure position is given by:

$$
P\left(y_{n}\right)=\frac{\left(I_{p h_{1}} \pm n_{1}\right)-\left(I_{p h_{2}} \pm n_{2}\right)}{\left(I_{p h_{1}} \pm n_{1}\right)+\left(I_{p h_{2}} \pm n_{2}\right)} \cdot \frac{L}{2} \Rightarrow P_{\max }\left(y_{n}\right)=\frac{I_{p h_{1}}-I_{p h_{2}}}{I_{p h_{1}}+I_{p h_{2}}-2 n} \cdot \frac{L}{2}, \text { for } n_{1}=n_{2}=n
$$


where $n_{1}$ and $n_{2}$ are the absolute noise detected at each of the element terminals and $L$ is the length of each line. Thus, the position of an image line projected in the plane $z-y$ is determined by $P\left(y_{n}\right)$ obtained by the 128 stripes and related to the currents detected by the MX8 connected to the terminals of integrated arrays.

The detection threshold limit will depend on the signal to noise ratio $(S / N)$, which is given by $S / N=\frac{I_{p h_{1}}+I_{p h_{2}}}{2 n}$. Thus, the positional resolution $(d P)$ depends on the active length of each sensing element and on $(S / N): d P \approx \frac{L}{2 S / N}$.

Once established the proper $S / N$ ratio, the performance of the 128 psd arrays is mainly dependent on the maximum distance at which a light spot from each of the collecting electrodes can be detected with a linear correlation between the spatial position and the lateral photocurrent measured [70].

As we aim to use these devices to supply planar information about 3-D objects (images) we should also define the Modulation Transfer Function (MTF) as the appropriate image quality criteria in the frequency spatial domain (specifying resolution and perceived image sharpness) [72]. That is, the contrast at a given spatial frequency relative to low frequencies.

In this case, the spatial frequency $(v)$ is typically measured in cycles or line pairs per millimetre $(\mathrm{lp} / \mathrm{mm})$. Therefore, high spatial frequencies correspond to fine image details. In our case, MTF will correspond to how well the input signal is preserved after being imaged. To do so we determine the Fast Fourier Transform of the signal and convert it into the frequency domain to define the pattern conditions that lead to proper spatial signal discrimination. That is:

$$
\operatorname{MTF}(v) \approx \frac{I_{\max }(v)-I_{\min }(v)}{I_{\max }(v)+I_{\text {min }}(v)}
$$


where $I_{\max }$ and $I_{\min }$ correspond to maximum and minimum currents discriminated between two consecutive spatial points. Thus, proper image plane resolution will correspond to the inverse of $v$ for which MTF has some meaning concerning image preservation and metric details. Finally, we have to consider the device nonlinearity of each strip (position detection error) $(\delta):$

$\delta=2 \sigma / F$

where $\sigma$ is the rms (root mean square) deviation from the regression line data and $F$ is the full scale measured.

\subsubsection{Integrated $128 \mathrm{psd}$ arrays performances}

The process conditions selected for fabricating the integrated psd arrays were the same used to fabricate the solar cells. Thus, once established the proper sensor geometry and before performing any measurement the conditions for light illumination of the array were defined. The detailed information concerning the detection platform and the integrated array is given in Tables 2 and 3.

The minimum light power allowable Pl, that permits a good linear correlation with a spatial detection error below $\pm 4 \%$, was approximately $50 \mathrm{nW} /$ line for the integrated devices under analysis.

To determine the image plane resolution the Modulation Transfer Function (MTF) required to preserve proper image detail and information must be known. Following equation (5) this means that MTF=0 when $v=2000 \mathrm{lp} / \mathrm{mm}$. Taking into account that the array has 128 elements we reach the set of data depicted in Figure 13. Considering that for a good image plane resolution MTF $\leq 10 \%$, we obtain the maximum $v$ at about $90 \mathrm{lp} / \mathrm{mm}$, from which we estimate that $I_{\max } / I_{\min } \geq 1.2$, to get a sharp image. Besides that, taking into account the laser 


\subsection{Thin film transistors}

The performances of the ns-Si:H TFTs analyzed using different dielectrics and channel lengths are summarized in Tables 4 and 5 and Figure 10. Overall, we notice a significant progress since the first device reported by LeComber et al [11] and the present values are amongst the highest found in the literature for a-Si:H [73-79] or nanostructured silicon TFTs [80-82]. The improvement observed on the TFTs performance is mainly related to two factors: lower growth rate used and the reduced hydrogen bombardment at the growing surface, which reduce defects.

For devices produced using ATO as the dielectric, the maximum on/off ratio was estimated since the transfer curve in the linear regime is not totally defined for source and drain current $\left(\mathrm{I}_{\mathrm{DS}}\right)$ below $10^{-12}$ A. This effect is now under investigation and seems to be induced by ATO and does not correspond to measuring limitations. Thus, we can only say that the on/off ratio is higher than $10^{7}$. Also the sub-threshold slope calculation is affected by the incomplete definition of the $\mathrm{I}_{\mathrm{DS}}$ current below $10^{-12} \mathrm{~A}$.

The data of ns-Si:H TFTs using thermally oxidized silicon and hafnium oxide as dielectric are also depicted in Figure 10a). The electrical characteristics of the devices produced on $\mathrm{SiO}_{2}$ (see Table 4) are even better when compared with those using ATO. The field effect mobility 
is now $1.24 \mathrm{~cm}^{2} \cdot \mathrm{V}^{-1} \cdot \mathrm{s}^{-1}$, while the $\mathrm{I}_{\mathrm{DS}}$ is well defined down to $10^{-14} \mathrm{~A}$, closer to the semiconductor analyser measuring limit. So we can clearly state that the on/off ratio is well above $10^{7}$, which confirms that the dark conductivity of ns-Si:H layer is low, allowing off currents on TFTs below 10fA. The threshold voltage is slightly higher when compared with ATO devices. This can be explained by the lower capacitance of $\mathrm{SiO}_{2}$, which is $34 \mathrm{nF} . \mathrm{cm}^{-2}$, on a $100 \mathrm{~nm}$ thick layer, when compared to the $64 \mathrm{nFcm}^{-2}$ of ATO. Besides this we must also take into account that the gate electrode is different, which contributes to changes on the $V_{T}$ value.

TFTs integrating a high $\mathrm{k}$ dielectric such as $\mathrm{HfO}_{2}$ were also produced (see Figure 10a). For a thickness of $300 \mathrm{~nm}$ we found a capacitance of $50 \mathrm{nFcm}^{-2}$, corresponding to a dielectric constant around 17. The electrical performance exhibited by these devices is not so impressive, which is attributed to the high roughness of the dielectric surface. Despite being deposited at room temperature, sputtered $\mathrm{HfO}_{2}$ normally presents a microcrystalline structure [53] which leads to a rough surface morphology in opposition to the smooth surfaces of amorphous ATO and $\mathrm{SiO}_{2}$. This contributes to the creation of defects on the dielectric/semiconductor interface side of the bottom gate of the TFTs, affecting $g_{m}$ and so $\mu_{F E}$ and $V_{T}$. Also the density of fixed charge in a $300 \mathrm{~nm} \mathrm{HfO}_{2}$ layer, which is normally positive and around $10^{12} \mathrm{~cm}^{-2}$ for sputtered films deposited at room temperature, is pushing the $V_{T}$ towards high values (5.19V).

Since the use of $\mathrm{SiO}_{2}$ leads to better electrical performance on ns-Si:H based TFTs, this dielectric was employed to monitor the effect of the channel length. A device with a W/L of $50 \mu \mathrm{m} / 50 \mu \mathrm{m}$ is compared with the one already presented in Figure $10 \mathrm{a}$ ), where the channel dimensions, $\mathrm{W} / \mathrm{L}$ are $15 \mathrm{um} / 15 \mathrm{um}$. Transfer characteristics on linear and saturation regimes as well as the extracted electrical parameters exhibited by these devices are respectively depicted in Figure 10b) and summarized in Table 4. The data obtained show that $g_{m}$ increases about 
$50 \%$, which corresponds to $\mu_{F E}=1.84 \mathrm{~cm}^{2} \cdot \mathrm{V}^{-1} \cdot \mathrm{s}^{-1}$. However, $V_{T}$ and $S$ for long channel TFTs are respectively $20 \%$ and $10 \%$ higher than the values obtained in short channel TFTs. This behaviour is attributed to the effect of the contact resistance $\left(\mathrm{R}_{\mathrm{C}}\right)$ at source and drain regions that is known to negatively affect the device's mobility, since the effective source to drain voltage is given by $V_{D S}-R_{C} I_{D S}$ [83]. Besides affecting the mobility, the contact resistance induces an error in extracting the device power parameter and $V_{T}$ by the amount of $R_{C} I_{D S} / 2$. This limitation is more pronounced on short channel devices, since $\mathrm{I}_{\mathrm{DS}}$ is proportional to $\mathrm{V}_{\mathrm{DS}} / \mathrm{L}$. The highest field effect mobility value $\left(2.47 \mathrm{~cm}^{2} \cdot \mathrm{V}^{-1} \cdot \mathrm{s}^{-1}\right)$ was obtained for devices where the active layer was produced using an optimized grid with larger holes (named 50/50 $\mathrm{OG}$ - fig. 10c). In this case their diameter is 1.5 times larger than the ones used for fabricating the other devices, allowing a better balance of the hydrogen bombardment effect on the films properties. This is also reflected on the other electrical parameters determined from the transfer curve (see Table 5).

\section{Conclusions}

In this work we have focussed on the deposition of nanostructured silicon (ns-Si:H) by PECVD in the so-called transition region and have shown improved properties, in comparison with amorphous silicon, when included in diverse applications. The hydrogen exodiffusion evolution observed on samples produced in this transition region shows two peaks, one at low temperature $(698 \mathrm{~K})$ and other at high temperature $(840 \mathrm{~K})$, associated to $\mathrm{E}_{\mathrm{a}}$ of $87 \mathrm{KJ} / \mathrm{mol}$ and $135 \mathrm{KJ} / \mathrm{mol}$, which are completely different from the ones observed in either amorphous or conventional microcrystalline thin films. The micro-Raman spectroscopy data show that in the transition region the curves shift slightly towards higher wavenumber and becomes narrow, which could be explained by the incorporation of nanocrystallites or the existence of nanostructured aggregates in the film. The solar cells produced in a single chamber system 
show good quantum efficiency, current density $=14.48 \mathrm{~mA} / \mathrm{cm}^{2}$, short circuit voltage $=0.94$ $\mathrm{V}$, and fill factor $=0.67$, which corresponds to an efficiency of $9.12 \%$, under AM1.5 conditions.

We have also fabricated 128psd integrated array which is able to satisfy the requirements for 3-D image processing, with a 7 bit lateral digital resolution, speed rates up to 10000 frames per second, with a detection error below 5\%; an image deep resolution of about 2.5-0.2 $\mu \mathrm{m}$; a horizontal resolution ranging from 50-10 $\mu \mathrm{m}$; a linearity better than $99.9 \%$, and a frequency response better than $500 \mathrm{kHz}$. That is, the integrated array can process frame image in real time and fast enough to allow image inspection in a continuous manner.

The ns-Si:H TFT produced using a grid to control the ion bombardment during the growth process lead to devices with improved $\mu_{F E}$. Among the different types of dielectric used it can be seen that TFTs based on $\mathrm{SiO}_{2}$ exhibit the best $\mu_{\mathrm{FE}}\left(1.2 \mathrm{~cm}^{2} \cdot \mathrm{V}^{-1} . \mathrm{s}^{-1}\right)$, with on/off ratio higher than $10^{7}$ and $\mathrm{V}_{\mathrm{T}}$ close to $2 \mathrm{~V}$. It was also verified that these TFTs suffer from non negligible influence of source and drain contact resistance. This was verified on devices with longer channel, where $\mu_{\mathrm{FE}}$ is $\sim 1.84 \mathrm{~cm}^{2} . \mathrm{V}^{-1} . \mathrm{s}^{-1}$. The optimization of the grid holes dimension allowed the improvement of this value to $2.47 \mathrm{~cm}^{2} \cdot \mathrm{V}^{-1} \cdot \mathrm{s}^{-1}$. Another remarkable result concerns the use of other dielectric materials other than the conventional silicon oxide, silicon nitride or silicon oxynitride based ones. These are the so-called high k dielectric films, ATO and hafnia, where the results achieved indicate a clear window for further improvement on the TFTs performance.

\section{Acknowledgements}

The first author would like to thank the Dundee group and to pay tribute to Professor Walter Spear who introduced us to the fantastic world of applied disordered semiconductor technologies. The contribution for this special issue of the Philosophy Magazine is only 
possible due to the legacy left by Professor W. Spear, in the field of Applied Solid State

Physics especially undoped and doped amorphous silicon/germanium and their alloys that significantly contributed to the development of optoelectronic and electronic devices. The authors would also like to thank the financial support given by "Fundação para a Ciência e a Tecnologia" through pluriannual contract with CENIMAT, and projects PTDC/Fis/24274/2006, PTDC/EEA-ELC/74236/2006 and Qren Solar tiles.

\section{References}

[1] N. F. Mott, Advances in Physics 16 (1967), p. 49.

[2] N. F. Mott, Philosophical Magazine 19 (1969), p. 835.

[3] M. H. Cohen, Fritzsch.H and Ovshinsk.Sr, Physical Review Letters 22 (1969), p. 1065.

[4] W. E. Spear and P. G. LeComber, Solid State Communications 17 (1975), p. 1193.

[5] W. E. Spear and P. G. LeComber, Philosophical Magazine 33 (1976), p. 935.

[6] D. A. Anderson and W. E. Spear, Philosophical Magazine 35 (1977), p. 1.

[7] P. G. LeComber, W. E. Spear and D. Allan, Journal of Non-Crystalline Solids 32 (1979), p. 1.

[8] P. G. LeComber, D. I. Jones and W. E. Spear, Philosophical Magazine 35 (1977), p. 1173.

[9] P. G. LeComber and W. E. Spear, Physical Review Letters 25 (1970), p. 509.

[10] A. Madan, P. G. LeComber and W. E. Spear, Journal of Non-Crystalline Solids 20 (1976), p. 239.

[11] P. G. LeComber, W. E. Spear and A. Ghaith, Electronics Letters 15 (1979), p. 179.

[12] D. L. Staebler and C. R. Wronski, Journal of Applied Physics 51 (1980), p. 3262.

[13] S. R. Ovshinsky and A. Madan, Nature 276 (1978), p. 482.

[14] W. E. Spear, G. Willeke, P. G. LeComber and A. G. Fitzgerald, Journal De Physique 42 (1981), p. 257.

[15] Y. Nagata, A. Kunioka and S. Yamazaki, Applied Physics Letters 38 (1981), p. 142.

[16] H. Richter, Z. P. Wang and L. Ley, Solid State Communications 39 (1981), p. 625.

[17] P. R. I. Cabarrocas, S. Hamma, S. N. Sharma, G. Viera, E. Bertran and J. Costa, Journal of Non-Crystalline Solids 230 (1998), p. 871.

[18] J. M. Pearce, R. J. Koval, A. S. Ferlauto, R. W. Collins, C. R. Wronski, J. Yang and S. Guha, Applied Physics Letters 77 (2000), p. 3093.

[19] D. E. Carlson and C. R. Wronski, Applied Physics Letters 28 (1976), p. 671.

[20] P. G. LeComber and W. E. Spear, Semiconductors and Semimetals 21 (1984), p. 89.

[21] L. E. Antonuk, J. Yorkston, J. Boudry, M. J. Longo, J. Jimenez and R. A. Street, Ieee Transactions on Nuclear Science 37 (1990), p. 165.

[22] H. Kakinuma, M. Sakamoto, Y. Kasuya and H. Sawai, Ieee Transactions on Electron Devices 37 (1990), p. 128.

[23] J. Wind, G. Krotz, R. Schmiedgen, W. Legner, V. Hechtenberg and G. Muller, Sensors and Actuators a-Physical 36 (1993), p. 187.

[24] R. M. Ambrosi, G. W. Fraser, B. Feller, R. Street, J. I. W. Watterson, P. White and G. Downing, Nuclear Instruments \& Methods in Physics Research Section a-Accelerators Spectrometers Detectors and Associated Equipment 500 (2003), p. 351. 
[25] S. Zhang, L. Raniero, E. Fortunato, L. Pereira, H. Aguas, L. Ferreira and R. Martins, Amorphous silicon based p-i-i-n structure for color sensor, In: R. W. T. P. C. K. M. C. R. B. R. Collins, Editor, Symposium on Amorphous and Nanocrystalline Silicon Science and Technology held at the 2005 MRS Spring Meeting, San Francisco, CA (2005).

[26] P. G. LeComber, A. E. Owen, W. E. Spear, J. Hajto, A. J. Snell, W. K. Choi, M. J. Rose and S. Reynolds, Journal of Non-Crystalline Solids 77-8 (1985), p. 1373.

[27] E. Fortunato, R. Martins, I. Ferreira, M. Santos, A. Macarico and L. Guimaraes, Journal of Non-Crystalline Solids 115 (1989), p. 120.

[28] E. Fortunato, G. Lavareda, M. Vieira and R. Martins, Review of Scientific Instruments 65 (1994), p. 3784.

[29] S. Arimoto, H. Yamamoto, H. Ohno and H. Hasegawa, Journal of Applied Physics 57 (1985), p. 4778.

[30] R. Martins, P. Baptista, L. Silva, L. Raniero, G. Doria, R. Franco and E. Fortunato, Journal of Non-Crystalline Solids 354 (2008), p. 2580.

[31] R. Martins, P. Baptista, L. Raniero, G. Doria, L. Silva, R. Franco and E. Fortunato, Applied Physics Letters 90 (2007).

[32] R. Martins, H. Aguas, I. Ferreira, E. Fortunato, S. Lebib, P. R. I. Cabarrocas and L. Guimaraes, Chemical Vapor Deposition 9 (2003), p. 333.

[33] S. Zhang, X. Liao, Y. Xu, R. Martins, E. Fortunato and G. Kong, Journal of NonCrystalline Solids 338-40 (2004), p. 188.

[34] L. Raniero, H. Aguas, L. Pereira, E. Fortunato, I. Ferreira and R. Martins, Advanced Materials Forum 455-456 (2004), p. 104.

[35] J. P. M. Schmitt, Journal of Non-Crystalline Solids 59-6 (1983), p. 649.

[36] B. Drevillon, J. Perrin, J. M. Siefert, J. Huc, A. Lloret, G. Derosny and J. P. M. Schmitt, Applied Physics Letters 42 (1983), p. 801.

[37] R. Martins, J. Figueiredo, V. Silva, H. Aguas, F. Soares, A. Marques, I. Ferreira and E. Fortunato, Journal of Non-Crystalline Solids 299 (2002), p. 1283.

[38] E. Fortunato, L. Pereira, H. Aguas, I. Ferreira and R. Martins, Proceedings of the Ieee 93 (2005), p. 1281.

[39] T. Tsukada, Active-Matrix Liquid-Crystal Displays, in The Technology and applications of amorphous silicon, R. A. Street, ed., Spring Verlagen, NY, 2000, p. 7.

[40] R. Martins, A. Macarico, M. Vieira, I. Ferreira and E. Fortunato, Philosophical Magazine B-Physics of Condensed Matter Statistical Mechanics Electronic Optical and Magnetic Properties 76 (1997), p. 249.

[41] L. Raniero, I. Ferreira, E. Fortunat and R. Martins, High Temperature Material Processes 11 (2007), p. 575.

[42] J. H. Park, J. B. Choi, H. Y. Kim, K. Y. Lee and J. Y. Lee, Thin Solid Films 266 (1995), p. 129.

[43] H. Aguas, L. Raniero, L. Pereira, E. Fortunato and R. Martins, Thin Solid Films 45152 (2004), p. 264.

[44] H. E. Kissinger, Analytical Chemistry 29 (1957), p. 1702.

[45] L. Raniero, I. Ferreira, H. Aguas, S. Zhang, E. Fortunato and R. Martins, Study of a$\mathrm{SiC}: \mathrm{H}$ buffer layer on nc-Si/a-Si : $\mathrm{H}$ solar cells deposited by PECVD technique, Conference Record of the Thirty-First Ieee Photovoltaic Specialists Conference - 2005 (2005).

[46] S. Guha, Multijunction Solar Cells and Modules in Technology and applications of amorphous silicon., R. A. Street, ed., Springer, NY, 2000, p. 252.

[47] R. Martins, I. Ferreira, H. Aguas, V. Silva, E. Fortunato and L. Guimaraes, Solar Energy Materials and Solar Cells 73 (2002), p. 39. 
[48] L. Raniero, S. Zhang, H. Aguas, I. Ferreira, R. Igreja, E. Fortunato and R. Martins, Thin Solid Films 487 (2005), p. 170.

[49] J. Springer, B. Rech, W. Reetz, J. Muller and M. Vanecek, Solar Energy Materials and Solar Cells 85 (2005), p. 1.

[50] R. Martins and E. Fortunato, Journal of Applied Physics 78 (1995), p. 3481.

[51] E. Fortunato, F. Soares, P. Teodoro, N. Guimaraes, M. Mendes, H. Aguas, V. Silva and R. Martins, Thin Solid Films 337 (1999), p. 222.

[52] H. Aguas, L. Pereira, L. Raniero, D. Costa, E. Fortunato and R. Martins, Journal of Non-Crystalline Solids 352 (2006), p. 1787.

[53] L. Pereira, P. Barquinha, E. Fortunato, R. Martins, D. Kang, C. J. Kim, H. Lim, I. Song and Y. Park, Thin Solid Films 516 (2008), p. 1544.

[54] P. R. I. Cabarrocas, A. F. I. Morral, S. Lebib and Y. Poissant, Pure and Applied Chemistry 74 (2002), p. 359.

[55] E. Fortunato, A. Goncalves, A. Marques, A. Pimentel, P. Barquinha, H. Aguas, L. Pereira, L. Raniero, G. Goncalves, I. Ferreira and R. Martins, Advanced Materials Forum 514-516 (2006), p. 3.

[56] E. Fortunato, V. Assuncao, A. Marques, A. Goncalves, H. Aguas, L. Pereira, I. Ferreira, F. M. B. Fernandes, R. J. C. Silva and R. Martins, Advanced Materials Forum 455-456 (2004), p. 12.

[57] E. Fortunato, A. Goncalves, V. Assuncao, A. Marques, H. Aguas, L. Pereira, I. Ferreira and R. Martins, Thin Solid Films 442 (2003), p. 121.

[58] L. Raniero, I. Ferreira, A. Pimentel, A. Goncalves, P. Canhola, E. Fortunato and R. Martins, Thin Solid Films 511 (2006), p. 295.

[59] H. Aguas, V. Silva, E. Fortunato, S. Lebib, P. R. I. Cabarrocas, I. Ferreira, L. Guimaraes and R. Martins, Japanese Journal of Applied Physics Part 1-Regular Papers Short Notes \& Review Papers 42 (2003), p. 4935.

[60] R. Martins, V. Silva, I. Ferreira, A. Domingues and E. Fortunato, Vacuum 56 (2000), p. 25 .

[61] R. Martins, H. Aguas, I. Ferreira, E. Fortunato, L. Raniero and P. R. I. Cabarrocas, Advanced Materials Forum 455-456 (2004), p. 100.

[62] T. Ohira, O. Ukai and M. Noda, Surface Science 458 (2000), p. 216.

[63] E. Fortunato, L. Raniero, L. Silva, A. Goncalves, A. Pimentel, P. Barquinha, H. Aguas, L. Pereira, G. Goncalves, I. Ferreira, E. Elangovan and R. Martins, Solar Energy Materials and Solar Cells 92 (2008), p. 1605.

[64] P. Kumar, F. Zhu and A. Madan, Electrical and structural properties of nanocrystalline silicon intrinsic layers for nano-crystalline silicon solar cells prepared by very high frequency plasma chemical vapor deposition, Symposium on Materials in Clean Power Systems II held at the 2007 TMS Annual Conference and Exposition, Orlando, FL (2008).

[65] A. Stavrides, A. Kunrath, J. Hu, R. Treglio, A. Feldman, B. Marsen, B. Cole, E. Miller and A. Madan, Use of amorphous silicon tandem junction solar cells for hydrogen production in a photoelectrochemical cell, In: L. Vayssieres, Editor, Conference on Solar Hydrogen and Nanotechnology, San Diego, CA (2006).

[66] C. S. Jiang, B. Yan, Y. Yan, C. W. Teplin, R. Reedy, H. R. Moutinho, M. M. AlJassim, J. Yang and S. Guha, Effect of $\mathrm{P}$ incorporation on aggregation of nanocrystallites in amorphous and nanocrystalline mixed-phase silicon thin films, 22nd International Conference on Amorphous and Nanocrystalline Semiconductors, Breckenridge, CO (2007).

[67] S. Guha, Manufacturing technology of amorphous and nanocrystalline silicon solar cells, In: K. L. S. D. K. Narasimhan, Editor, 14th International Workshop on the 
Physics of Semiconductor Devices, Mumbai, INDIA (2007).

[68] C. S. Jiang, B. Yan, H. R. Moutinho, M. M. Al-Jassim, J. Yang and S. Guha, Light soaking and thermal annealing effects on the micro-electrical properties of amorphous and nanocrystalline mixed-phase silicon solar cells, In: V. M. S. N. A. Y. J. Z. H. W. Chu, Editor, Symposium on Amorphous and Polycrystalline Thin-Film Silicon Science and Technology held at the 2007 MRS Spring Meeting, San Francisco, CA (2007).

[69] B. Yan, G. Yue and S. Guha, Status of nc-Si : H solar cells at United Solar and roadmap for manufacturing a-Si : H and ne-Si : H based solar panels, In: V. M. S. N. A. Y. J. Z. H. W. Chu, Editor, Symposium on Amorphous and Polycrystalline ThinFilm Silicon Science and Technology held at the 2007 MRS Spring Meeting, San Francisco, CA (2007).

[70] R. Martins and E. Fortunato, Thin Film Position Sensitive Detectors: From 1D to 3D Applications in Technology and applications of amorphous silicon, R. A. Street, ed., Springer, NY, 2000, p. 342.

[71] F. E. Martins R., Amorphous silicon Position Sensors, in The Technology and Applications of Amorphous Silicon, R. Street, ed., Springer Verlag, NY, 2000, p. 342.

[72] J. E. Harvey, Handbook of Optics, McGraw-Hill, Inc, New York (1995).

[73] K. Parikh, K. Chung, B. Choi, J. C. Goh, J. M. Huh, Y. R. Song, N. Kim and J. Choi, Novel AC bias compensation scheme in hydrogenated amorphous silicon TFT for AMOLED Displays, 6th International Meeting on Information Displays/5th International Display Manufacturing Conference (IMID/IDMC 2006), Daegu, SOUTH KOREA (2006).

[74] S. F. Lin, A. J. Flewitt, W. I. Milne, R. B. Wehrspohn and M. J. Powell, Applied Physics Letters 86 (2005).

[75] R. B. Wehrspohn, M. J. Powell and S. C. Deane, Journal of Applied Physics 93 (2003), p. 5780.

[76] M. J. Powell, R. B. Wehrspohn and S. C. Deane, Nature of metastable and stable dangling bond defects in hydrogenated amorphous silicon, 19th International Conference on Amorphis and Microcrystalline Semiconductors (ICAMS 19), Old Nice, France (2001).

[77] B. Stannowski, R. E. I. Schropp, R. B. Wehrspohn and M. J. Powell, Amorphoussilicon thin-film transistors deposited by VHF-PECVD and hot-wire CVD, 19th International Conference on Amorphis and Microcrystalline Semiconductors (ICAMS 19), Old Nice, France (2001).

[78] B. Hekmatshoar, K. H. Cherenack, A. Z. Kattamis, K. Long, S. Wagner and J. C. Sturm, Applied Physics Letters 93 (2008).

[79] K. Ishibashi and M. Matsumura, Applied Physics Letters 41 (1982), p. 454.

[80] I. C. Cheng and S. Wagner, Self-aligned nanocrystalline silicon thin-film transistor with deposited $\mathrm{n}(+)$ source/drain layer, In: V. M. S. N. A. Y. J. Z. H. W. Chu, Editor, Symposium on Amorphous and Polycrystalline Thin-Film Silicon Science and Technology held at the 2007 MRS Spring Meeting, San Francisco, CA (2007).

[81] M. R. Esmaeili-Rad, A. Sazonov and A. Nathan, Journal of Applied Physics 103 (2008).

[82] A. Ahnood, K. Ghaffarzadeh, A. Nathan, P. Servati, F. Li, M. R. Esmaeili-Rad and A. Sazonov, Applied Physics Letters 93 (2008).

[83] E. B. K. Chan, D. Knipp, H. Stiebig, Semiconductor Science and Technology 22 (2007), p. 1213. 


\section{Figure Captions}

Figure 1. (a) Image of the 128 psd integrated array and of the (b) pcb where it will be mounted

Figure 2. (a) Schematic of the electrical interconnections between the sensor; the controller unit; the MX4 and the Computer where the acquisition data board exists;

(b) Global vision of the line inspection camera demonstrator used; (c) detailed information about the optical system. The numbers refer to: 1) Chassis; 2) pcb board that contains the sensor; 3) Lens (35-70 mm, f:1.4); 4) Laser line generator (635 nm)+ angular adjustment; 5) Connecting cable from the pcb board to the PC; 6) X-Y controlled table.

Figure 3. Schematic structure of bottom gate ns-Si:H TFTs integrating as dielectric: (a) aluminum oxide/titanium oxide multilayer (ATO) deposited by ALD; (b) thermal silicon oxide $\left(\mathrm{SiO}_{2}\right)$; (c) sputtered hafnium oxide $\left(\mathrm{HfO}_{2}\right)$

Figure 4. Micro-Raman spectra for the different set of silicon thin films produced.

Figure 5. Hydrogen evolution spectra for the set of silicon thin films processed. The illustrations shown aim to represent the atoms rearrangements within the different type of structures studied: a) microcrystalline films; b) nanostructured films; c) amorphous films.

Figure 6. Power density as a function of hydrogen dilution ratio used, showing the different conditions that lead to the production of materials where the amorphous or the microcrystalline phases dominate. In-between we can see the transition region.

Figure 7. Evolution of LT and HT hydrogen exodiffusion peak positions as function of power density, for $\mathrm{d}_{\mathrm{r}}=5 \%$.

Figure 8. (a) Cross section of the solar cell structure; b) J-V characteristic of the solar cell; (c) quantum efficiency curve for the produced solar cell.

Figure 9. Spatial resolution measurements preformed on a sensor with $0.25 \mu \mathrm{m}$ and $1.00 \mu \mathrm{m}$ steps.

Figure 10. (a) Transfer characteristics on linear regime for ns-Si:H TFT produced with the protection grid integrating different dielectrics; also plotted is the corresponding 
transconductance; (b) transfer characteristics on linear $\left(\mathrm{V}_{\mathrm{DS}}=1 \mathrm{~V}\right)$ and saturation regimes $\left(\mathrm{V}_{\mathrm{DS}}=10 \mathrm{~V}\right)$ for $\mathrm{ns}-\mathrm{Si}: \mathrm{H}$ TFT with different channel dimensions integrating $\mathrm{SiO}_{2}$ as dielectric. The plot of the transconductance for both channel lengths analysed is also shown.

Figure 11. Activation energy for nanostructured films processed in the transition region. Data from Figure 8 were fitted by equation 2 .

Figure 12. Schematic of the light line projected onto de integrated 128 psd arrays that contain the information of the object to be displayed.

Figure $13 . \mathrm{MTF}(\%)$ as a function of the spatial frequency.

Figure 14. (a) Image to be 3D scanned, showing the laser line projected on it; (b) collected image by the sensor, in real time, without any type of data treatment. 
Table 1

\begin{tabular}{|l|l|c|c|}
\hline \multicolumn{1}{|c|}{ Layers } & \multicolumn{1}{|c|}{ Thickness $(\mathrm{nm})$} & \multicolumn{1}{c|}{$\begin{array}{c}\text { Conductivity } \\
\left(\Omega^{-1} \mathrm{~cm}^{-1}\right)\end{array}$} & $\begin{array}{c}\text { Optical Gap } \\
(\mathrm{eV})\end{array}$ \\
\hline p-doped & $\approx 7,8 \pm 2 \mathrm{~nm}$ & $3,2 \times 10^{-6}$ & $1,94 \pm 0,01$ \\
\hline Buffer ${ }_{1}$ & $\approx 0,5 \mathrm{~nm}$ & ------ & $1,88 \pm 0,01$ \\
\hline Buffer 2 & $\approx 0,8 \mathrm{~nm}$ & ------ & $1,84 \pm 0,01$ \\
\hline Intrinsic & $\approx 270 \pm 10 \mathrm{~nm}$ & $6,12 \times 10^{-10}$ & $1,82 \pm 0,01$ \\
\hline n-doped & $\approx 25 \pm 5 \mathrm{~nm}$ & $2,46 \times 10^{-3}$ & 1,80 \\
\hline Back contact & $\approx 30 \mathrm{~nm}$ of Ag $+\approx 170 \mathrm{~nm}$ of Al & ------- & ---- \\
\hline $\begin{array}{l}\text { Gas mixture used: } \\
\text { p-layer }=1 \%\left(\mathrm{CH}_{4}\right)_{3} \mathrm{~B}_{2}+40 \% \mathrm{CH}_{4}+39 \% \mathrm{SiH}_{4}+20 \% \mathrm{H}_{2} ;\end{array}$ & $\begin{array}{l}\text { i-layer }=5 \% \mathrm{SiH}_{4}+95 \% \mathrm{H}_{2} \\
\text { Buffer }{ }_{1}=7 \% \mathrm{SiH}_{4}+8 \% \mathrm{CH}_{4}+85 \% \mathrm{H}_{2}\end{array}$ \\
Buffer & $=1 \% \mathrm{PH}_{3}+30 \% \mathrm{SiH}_{4}+28 \% \mathrm{H}_{2}+41 \% \mathrm{He}$ \\
\hline
\end{tabular}


Table 2.

\begin{tabular}{|c|c|c|c|c|c|c|c|}
\hline $\begin{array}{c}\text { Array } \\
\text { type }\end{array}$ & $\begin{array}{c}\text { Dimension } \\
{[\mathbf{m m}]}\end{array}$ & $\begin{array}{c}\text { Active } \\
\text { area } \\
{[\mathbf{m m}]}\end{array}$ & $\begin{array}{c}\text { Non-linearity } \\
{[\%]}\end{array}$ & $\begin{array}{c}\text { Line } \\
\text { resolution } \\
{[\boldsymbol{\mu m}]}\end{array}$ & $\begin{array}{c}\text { Working Light } \\
\text { wave number } \\
\text { range } \\
{[\mathbf{n m}]}\end{array}$ & $\begin{array}{c}\text { Frequency } \\
\text { response } \\
{[\mathbf{k H z}]}\end{array}$ & $\begin{array}{c}\text { NEP } \\
{\left[\mathbf{W} / \mathbf{H z}^{\mathbf{1}}\right]}\end{array}$ \\
\hline \hline 128 & $\begin{array}{c}\text { Chip carrier } \\
47 \times 47 \\
\text { Sensor } \\
30 \times 30\end{array}$ & $20 \times 12$ & $<2 \%$ & $<0.75$ & $500-680$ & $>500$ & $10^{-11}$ \\
\hline
\end{tabular}


Table 3.

\begin{tabular}{|l||l|}
\hline Open space distance $(\mathrm{h})$ & $40-6 \mathrm{~cm}$ \\
\hline Working range & $10-0.5 \mathrm{~cm}$ \\
\hline Sensor Deep resolution $(\mathrm{z})$ & $2.5-0.75 \mu \mathrm{m}$ \\
\hline Sensor horizontal resolution $(\mathrm{x})$ & $50-10 \mu \mathrm{m}$ \\
\hline Scanning speed $\left(\mathrm{v}_{\mathrm{y}}\right)$ & $<50 \mathrm{~cm} / \mathrm{s}$ \\
\hline Frequency response & $>500 \mathrm{kHz}$ \\
\hline Linearity & $>99,9 \%$ \\
\hline Lens aperture & 2.8 \\
\hline
\end{tabular}


Table 4.

\begin{tabular}{ccccc}
\hline Dielectric & $\begin{array}{c}\mu_{F E} \\
\left(\mathbf{c m}^{2} \cdot \mathbf{V}^{-1} \cdot \mathbf{s}^{-\mathbf{1}}\right)\end{array}$ & $\begin{array}{c}\boldsymbol{V}_{T} \\
(\mathbf{V})\end{array}$ & $\begin{array}{c}\boldsymbol{S} \\
(\mathbf{V} / \mathbf{d e c})\end{array}$ & $\boldsymbol{I}_{\text {on }} / \mathbf{I}_{\text {off }}$ \\
& 1.14 & 2.04 & 0.52 & $>10^{6}$ \\
\hline ATO & 1.24 & 2.35 & 0.45 & $>10^{7}$ \\
\hline $\mathbf{S i O}_{2}$ & 0.85 & 5.19 & 0.63 & $>10^{7}$ \\
\hline $\mathbf{H f O}_{2}$ & & & & \\
\hline
\end{tabular}


Table 5.

\begin{tabular}{ccccc}
\hline $\begin{array}{c}\text { W/L } \\
(\boldsymbol{\mu m})\end{array}$ & $\begin{array}{c}\mu_{F E} \\
\left(\mathbf{c m}^{2} \cdot \mathbf{V}^{-\mathbf{1}} \cdot \mathbf{s}^{-\mathbf{1}}\right)\end{array}$ & $\begin{array}{c}\boldsymbol{V}_{T} \\
(\mathbf{V})\end{array}$ & $\begin{array}{c}\boldsymbol{S} \\
(\mathbf{V} / \mathbf{d e c})\end{array}$ & $\boldsymbol{I}_{\text {on }} / \boldsymbol{I}_{\text {off }}$ \\
& & & & \\
\hline $\mathbf{1 5 / \mathbf { 1 5 }}$ & 1.24 & 2.35 & 0.45 & $>10^{7}$ \\
\hline $\mathbf{5 0 / 5 0}$ & 1.84 & 2.82 & 0.56 & $>10^{6}$ \\
\hline $\mathbf{5 0 / 5 0 ~ 0 G *}$ & 2.47 & 2.78 & 0.32 & $>10^{7}$ \\
\hline
\end{tabular}



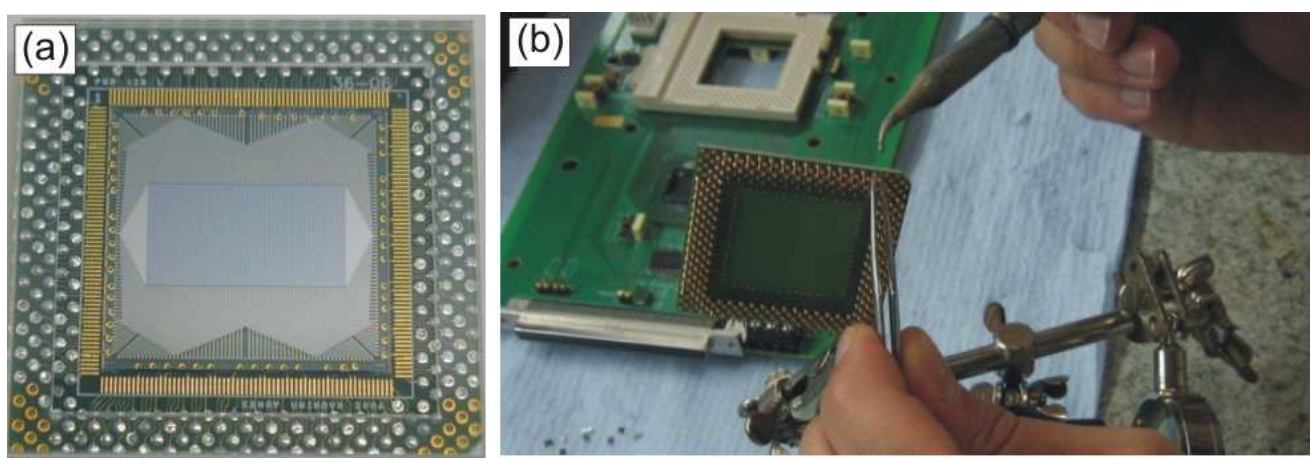

Figure 1. (a) Image of the 128 psd integrated array and of the (b) pcb where this will be mounted 

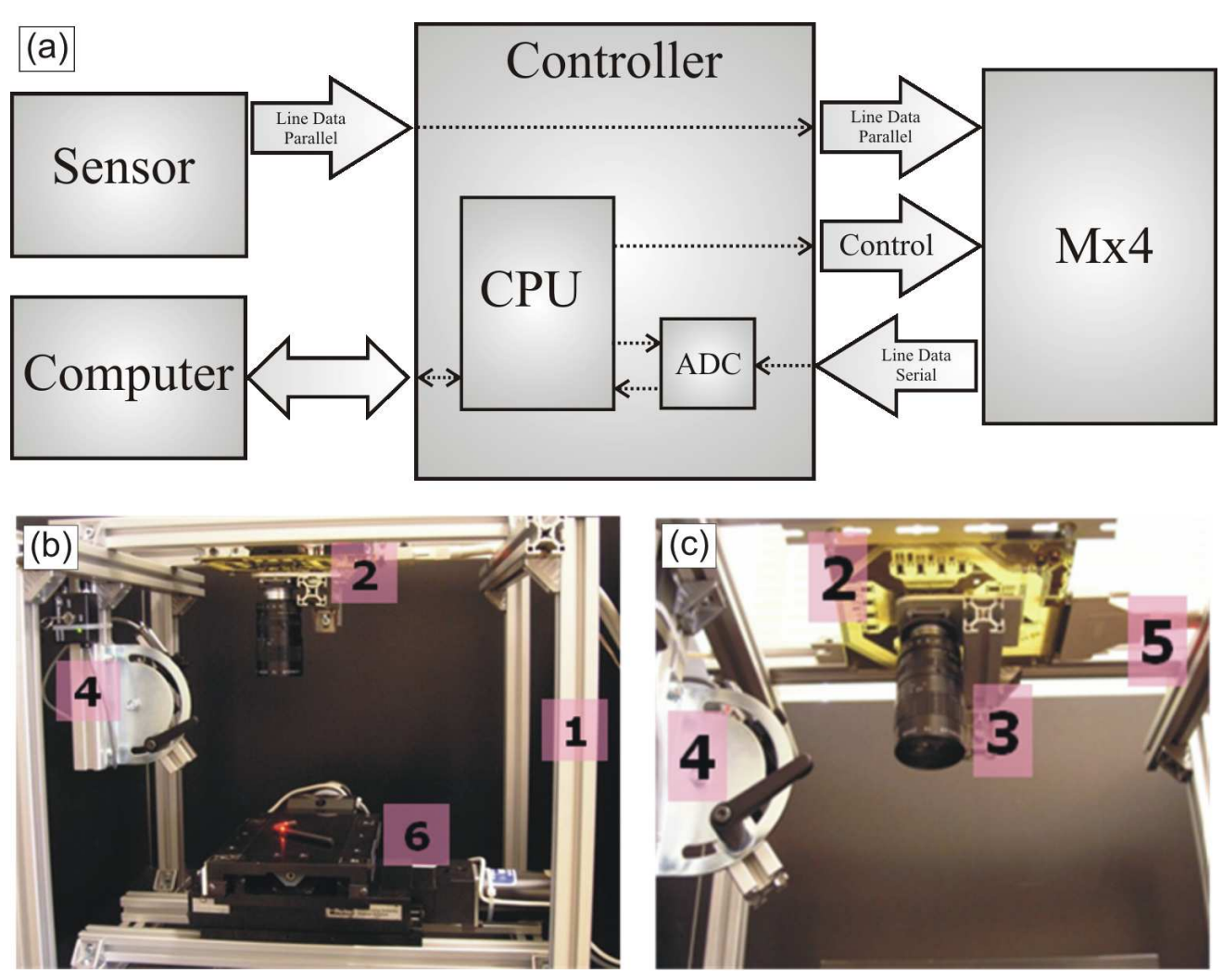

Figure 2. (a) Schematic of the electrical interconnections between the sensor; the controller unit; the MX4 and the Computer where it exists the acquisition data board;

(b) Global vision of the line inspection camera demonstrator used; (c) detailed information about the optical system. The numbers refer to: 1) Chassis; 2) pcb board that contains the sensor; 3) Lens (35-70 mm, f:1.4); 4) Laser line generator (635 nm)+ angular adjustment; 5) Connecting cable from the pcb board to the PC; 6$) \mathrm{X}-\mathrm{Y}$ controlled table. 
Figure 3. Schematic structure of bottom gate ns-Si:H TFTs integrating as dielectric: (a) aluminum oxide/titanium oxide multilayer (ATO) deposited by ALD; 


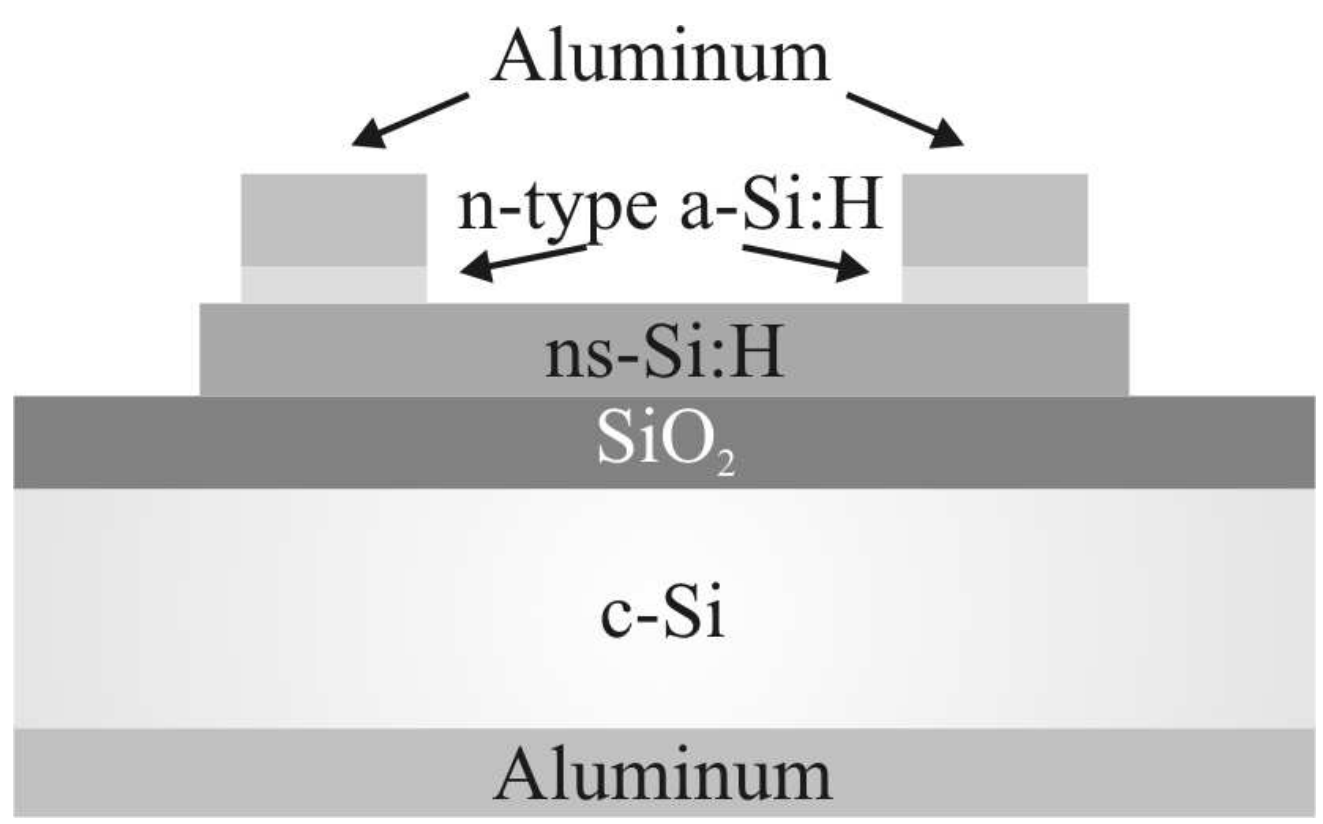

Figure 3. Schematic structure of bottom gate ns-Si:H TFTs integrating as dielectric: (b) thermal silicon oxide ( $\mathrm{SiO} 2)$; 
Figure 3. Schematic structure of bottom gate ns-Si:H TFTs integrating as dielectric: (c) sputtered hafnium oxide ( $\mathrm{HfO} 2)$ 


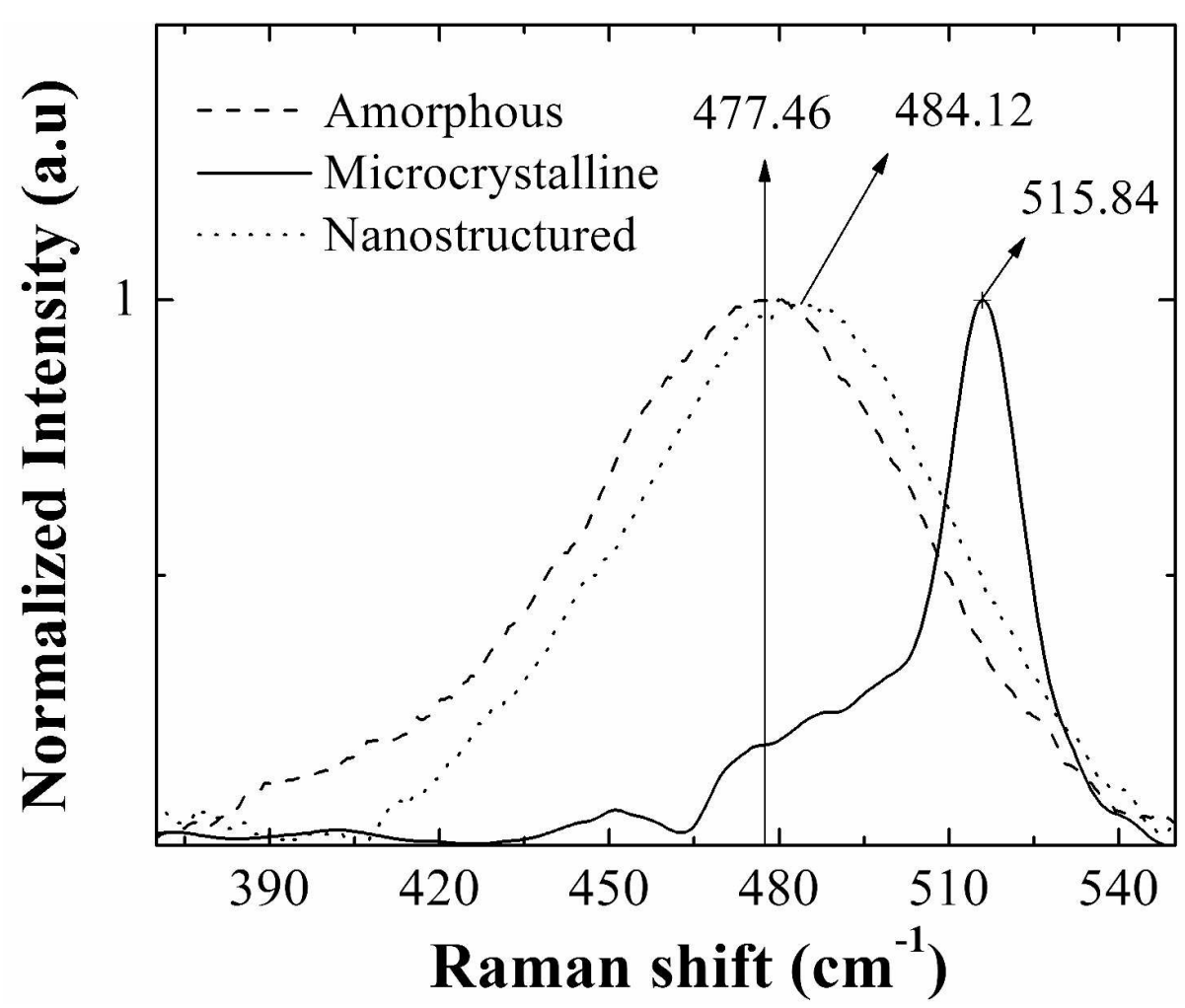

Figure 4. Micro-Raman spectra for the different set of silicon thin films produced. $269 \times 206 \mathrm{~mm}(300 \times 300 \mathrm{DPI})$ 

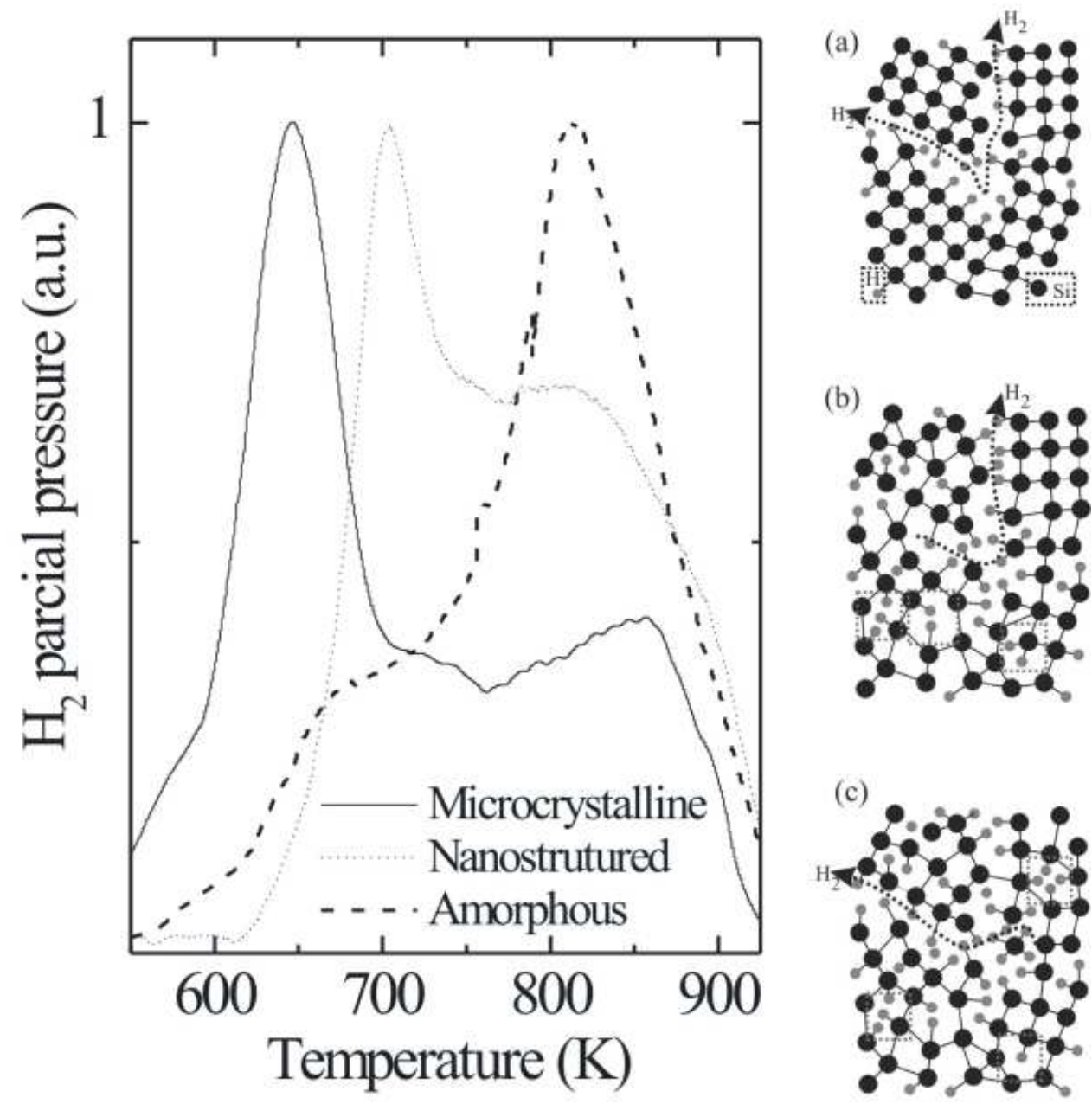

(b)

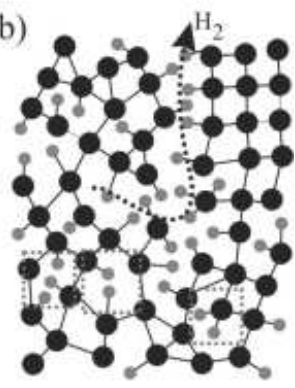

(c)

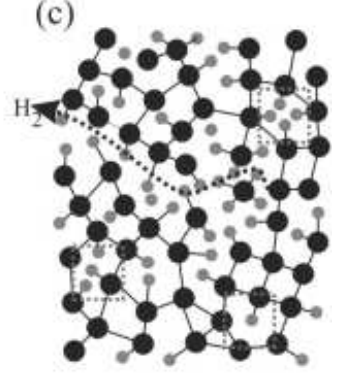

Figure 5. Hydrogen evolution spectra for the set of silicon thin films processed. The illustrations shown aim to represent the atoms rearrangements within the different type of structures studied: a) microcrystalline films; b) nanostructured films; c) amorphous films. 


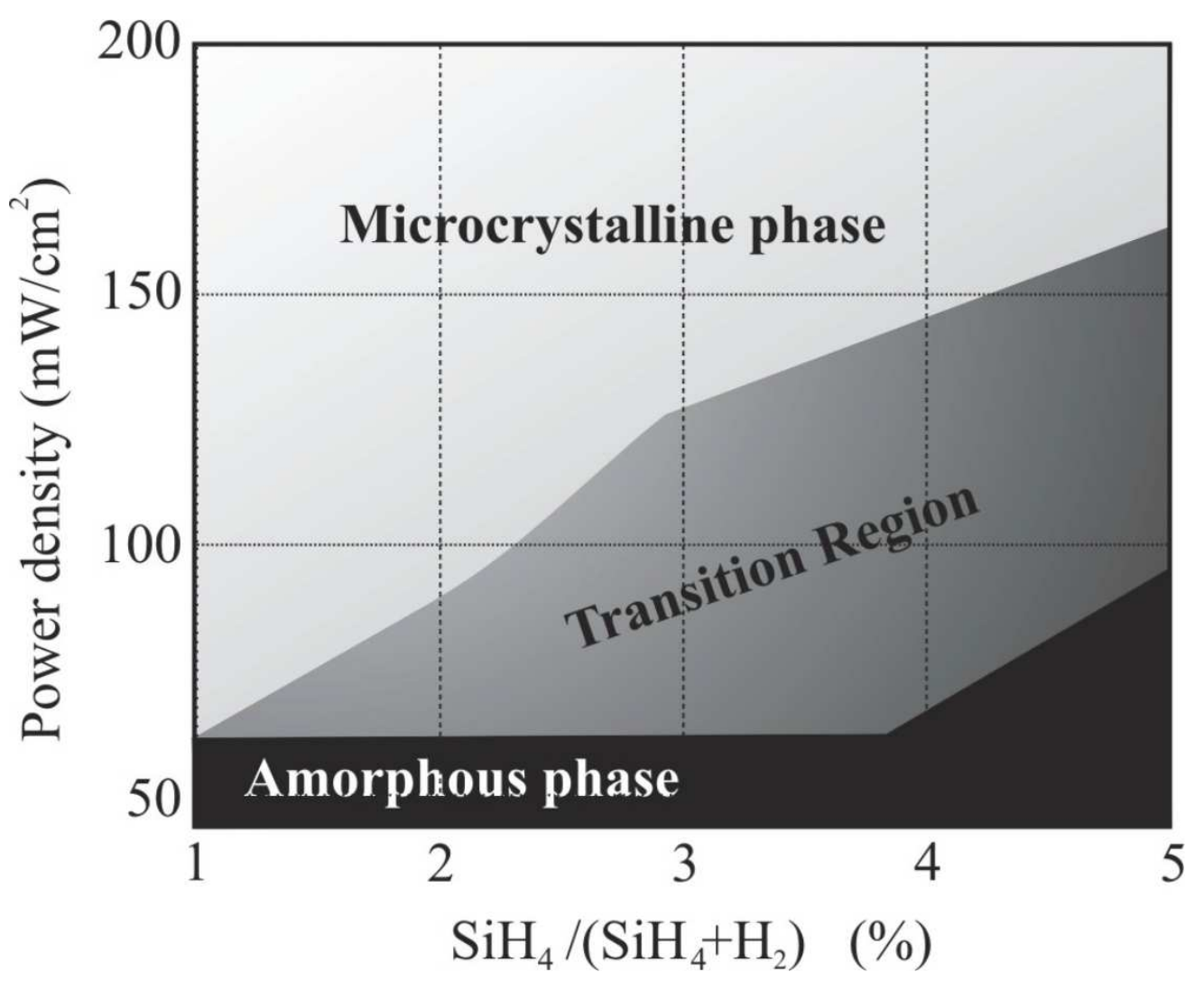

Figure 6. Power density as a function of hydrogen dilution ratio used, showing the different conditions that lead to the production of materials where the amorphous or the microcrystalline phases dominate. In-between we can se the transition region. 


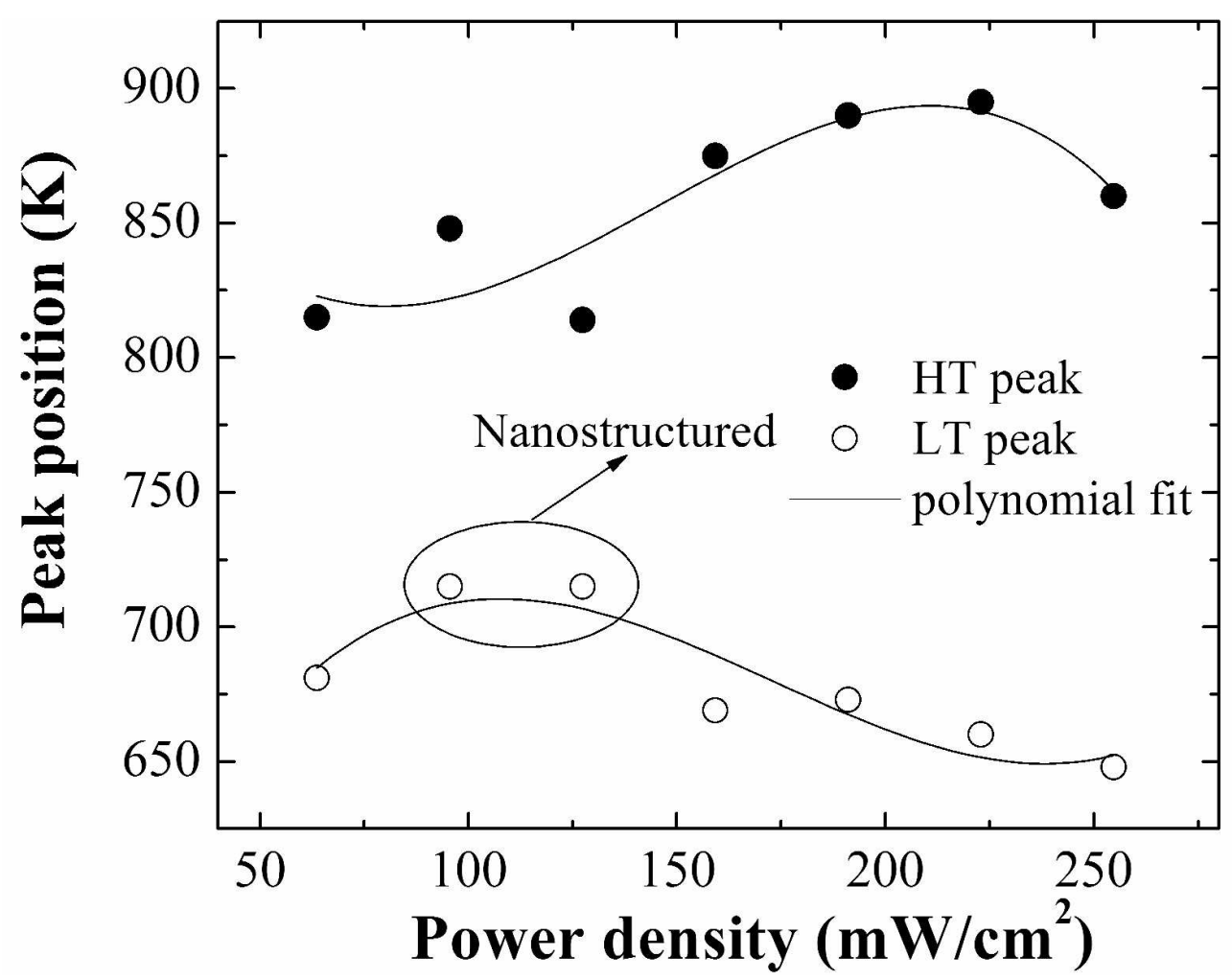

Figure 7. Evolution of LT and HT hydrogen exodiffusion peak positions as function of power density, for $d r=5 \%$. $269 \times 206 \mathrm{~mm}(300 \times 300$ DPI $)$ 


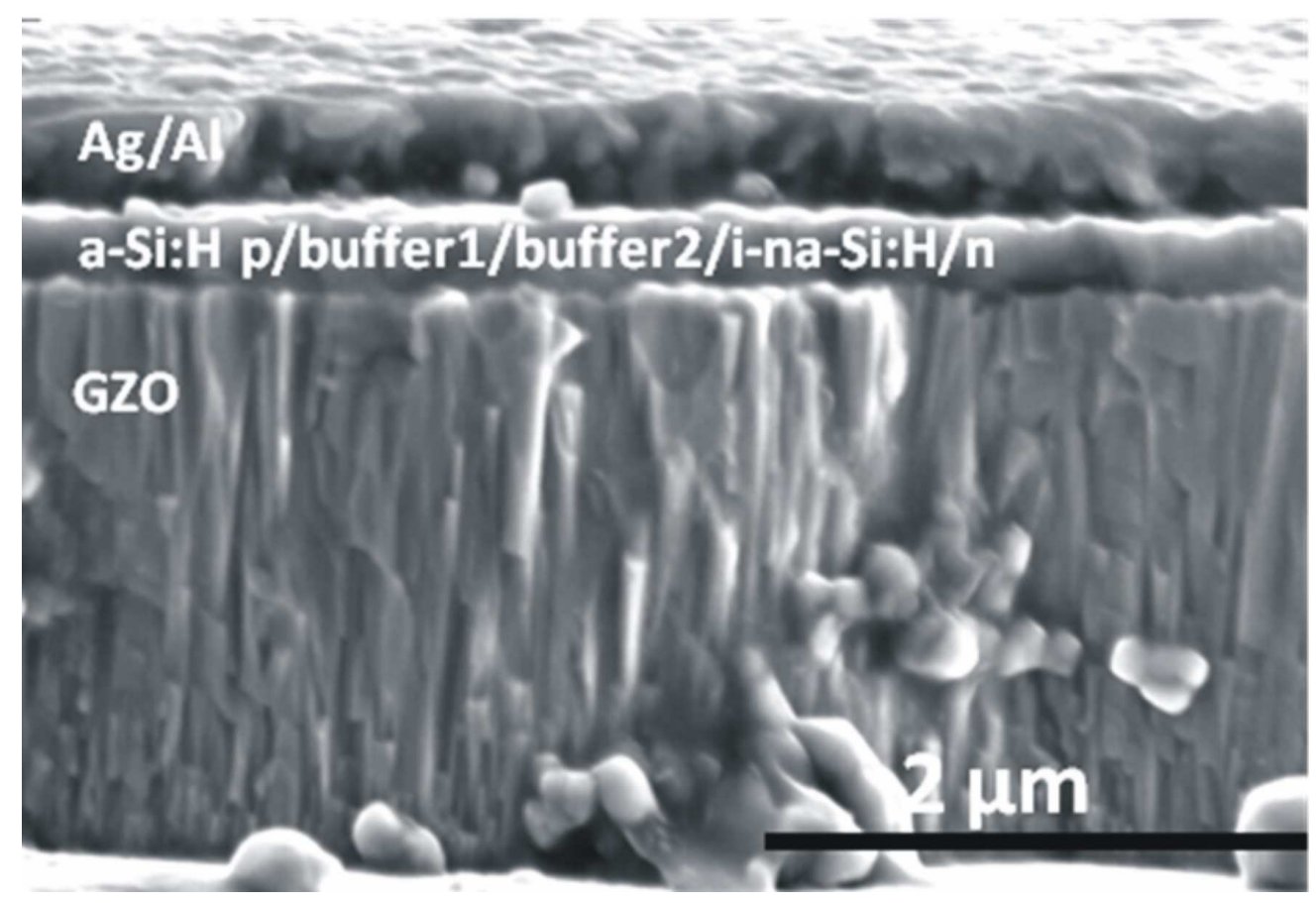

Figure 8. (a) Cross section of the solar cell structure; 


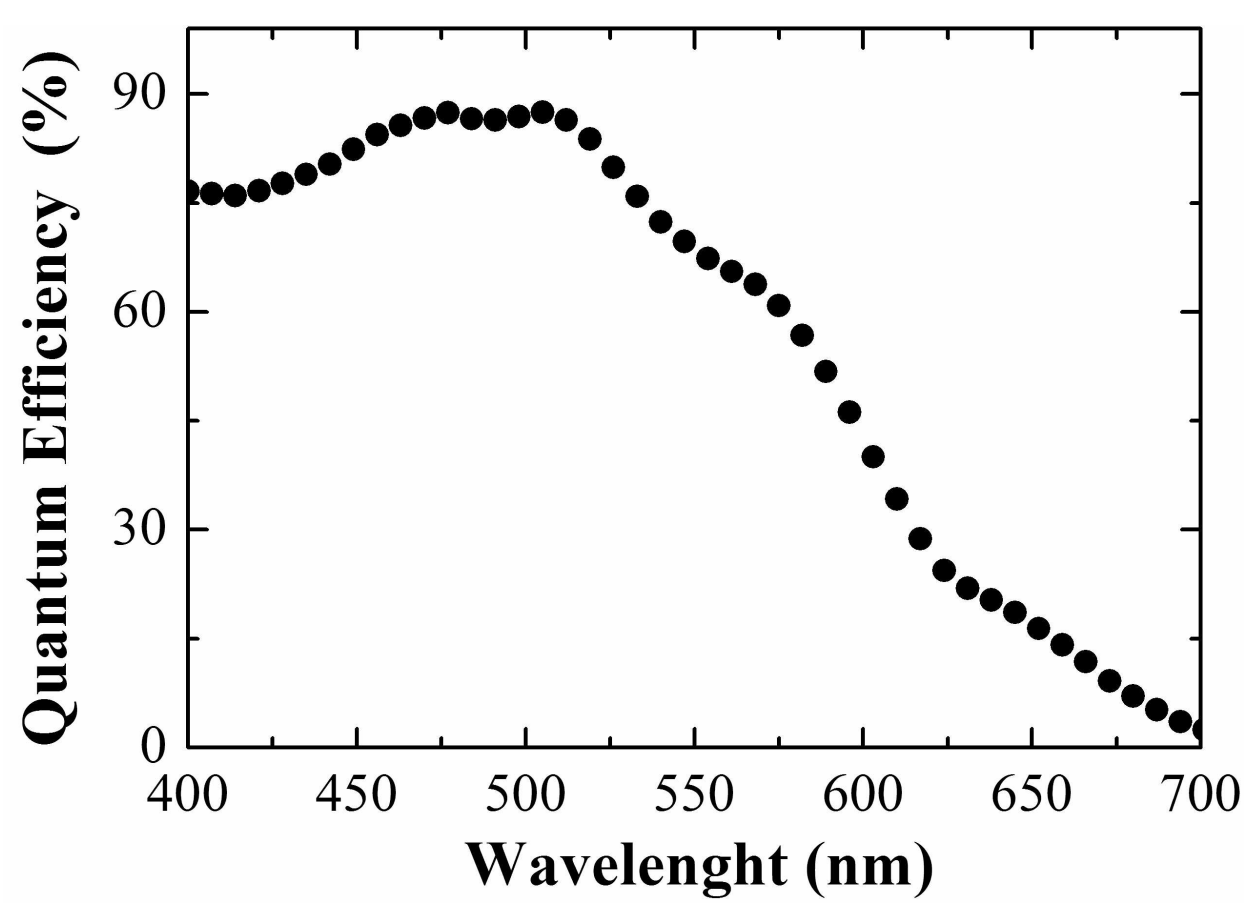

Figure 8. b) J-V characteristic of the solar cell; $226 \times 152 \mathrm{~mm}(300 \times 300 \mathrm{DPI})$ 


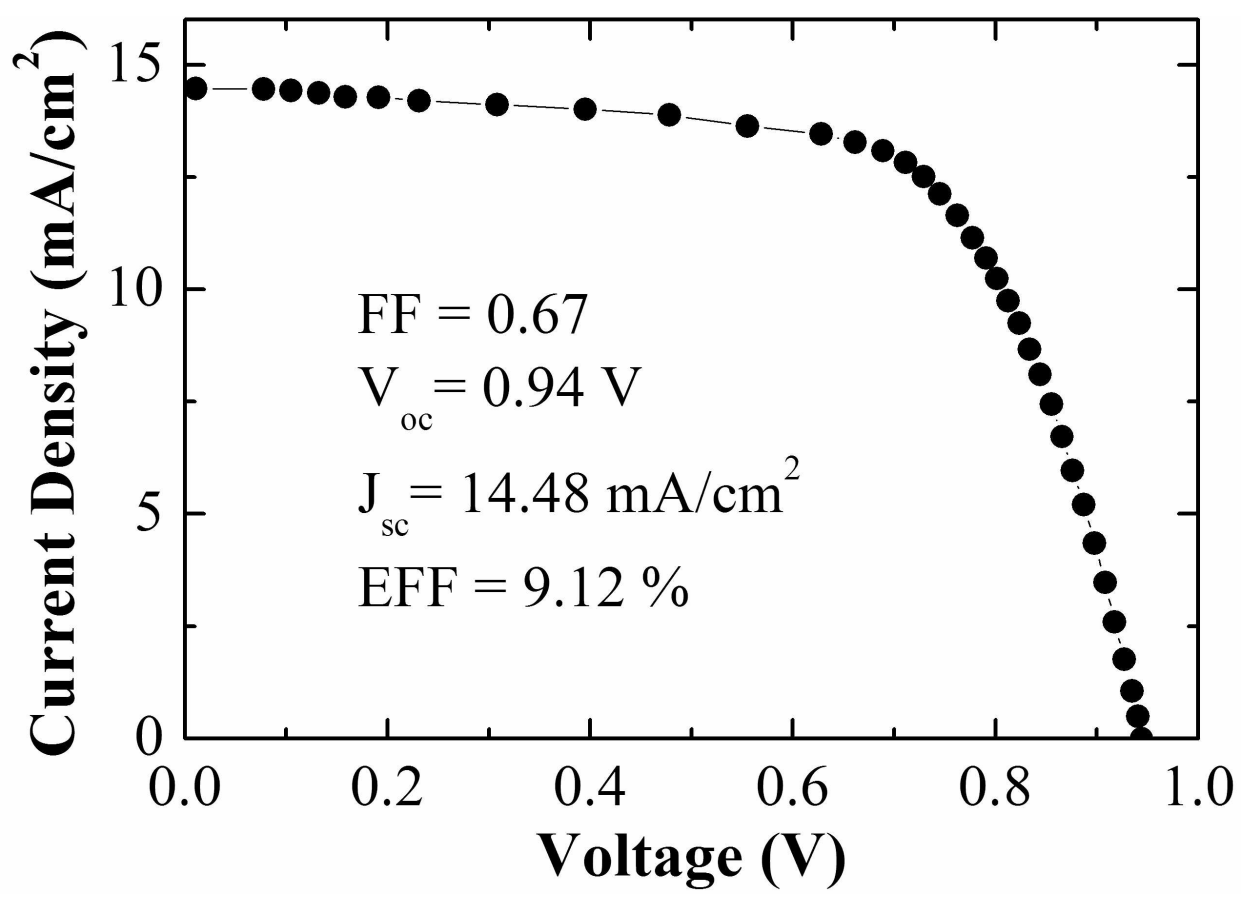

Figure 8. c) the quantum efficiency curve for the solar cell produced. $226 \times 152 \mathrm{~mm}(300 \times 300 \mathrm{DPI})$ 


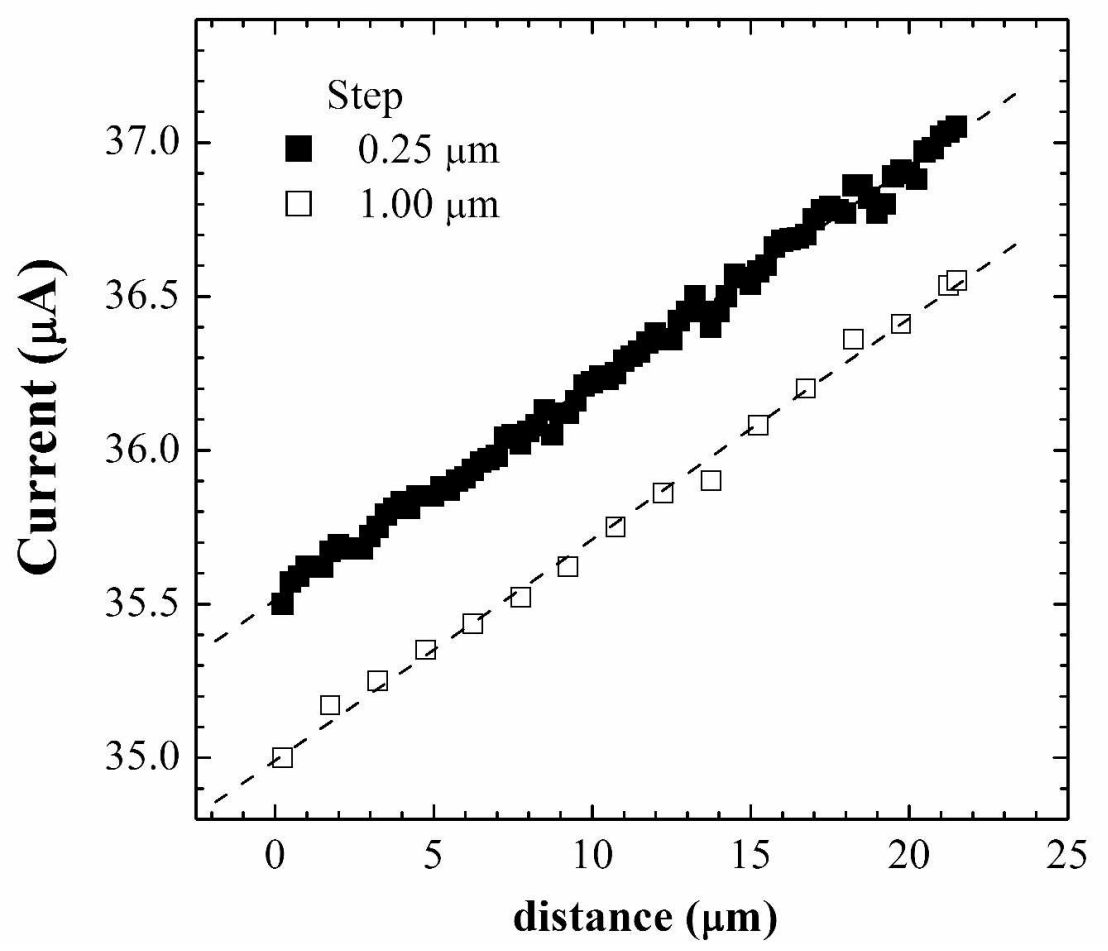

Figure 9. Spatial resolution measurements preformed on a sensor with $0.25 \mu \mathrm{m}$ and $1.00 \mu \mathrm{m}$ steps. $266 \times 206 \mathrm{~mm}$ (300 x 300 DPI) 


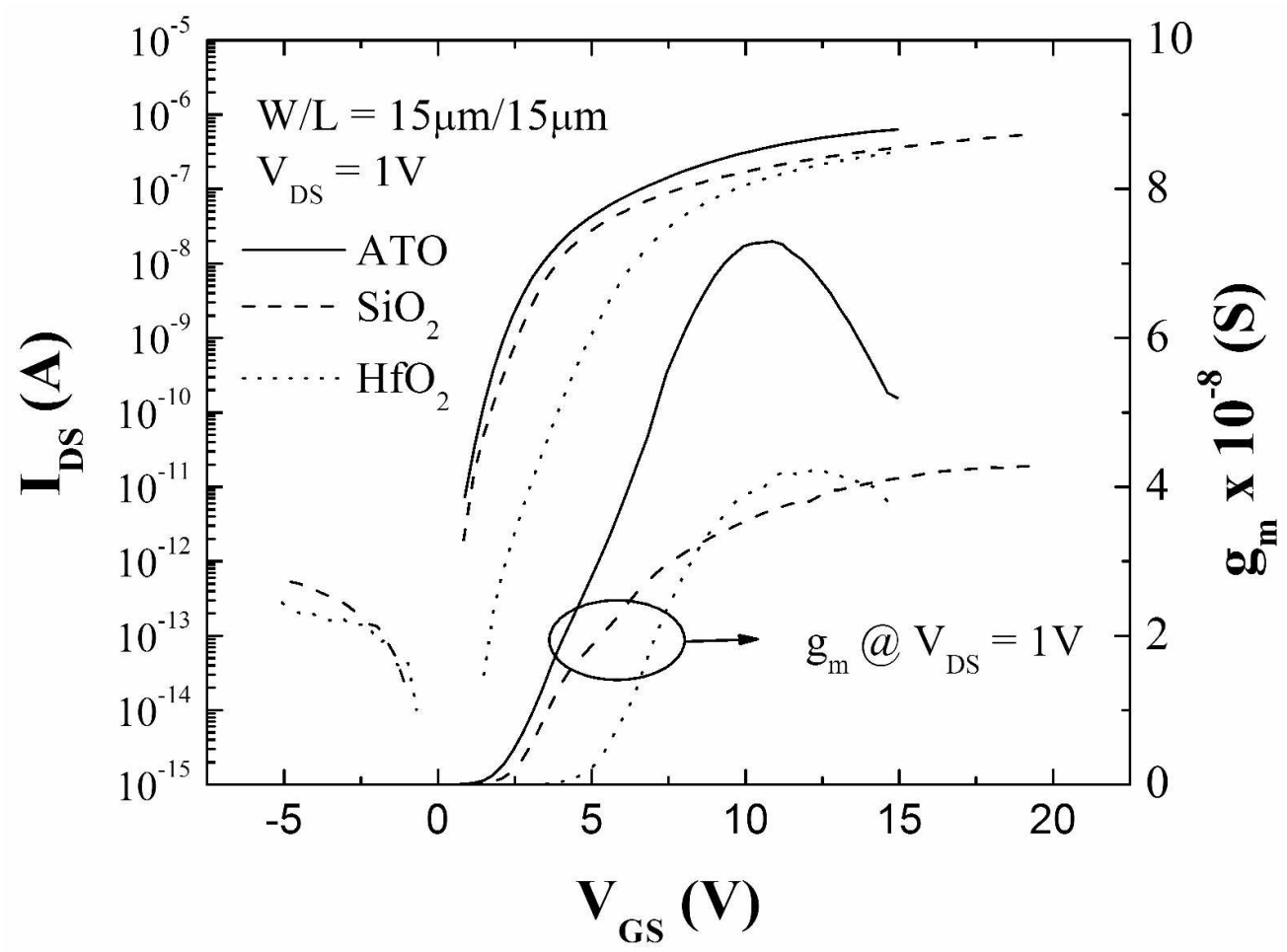

Figure 10. (a) Transfer characteristics on linear regime for ns-Si:H TFT produced with the protection grid integrating different dielectrics. There it is also plotted the corresponding transconductance; (b) transfer characteristics on linear $\left(V_{=1 \mathrm{~V}}\right)$ and saturation regimes $(\mathrm{V}=10 \mathrm{~V})$ for ns-Si:H TFT with different channel dimensions integrating $\mathrm{SiO}$ as dielectric. There, it is also shown the plot of the transconductance for both channel lengths analysed. $269 \times 206 \mathrm{~mm}(300 \times 300$ DPI $)$ 


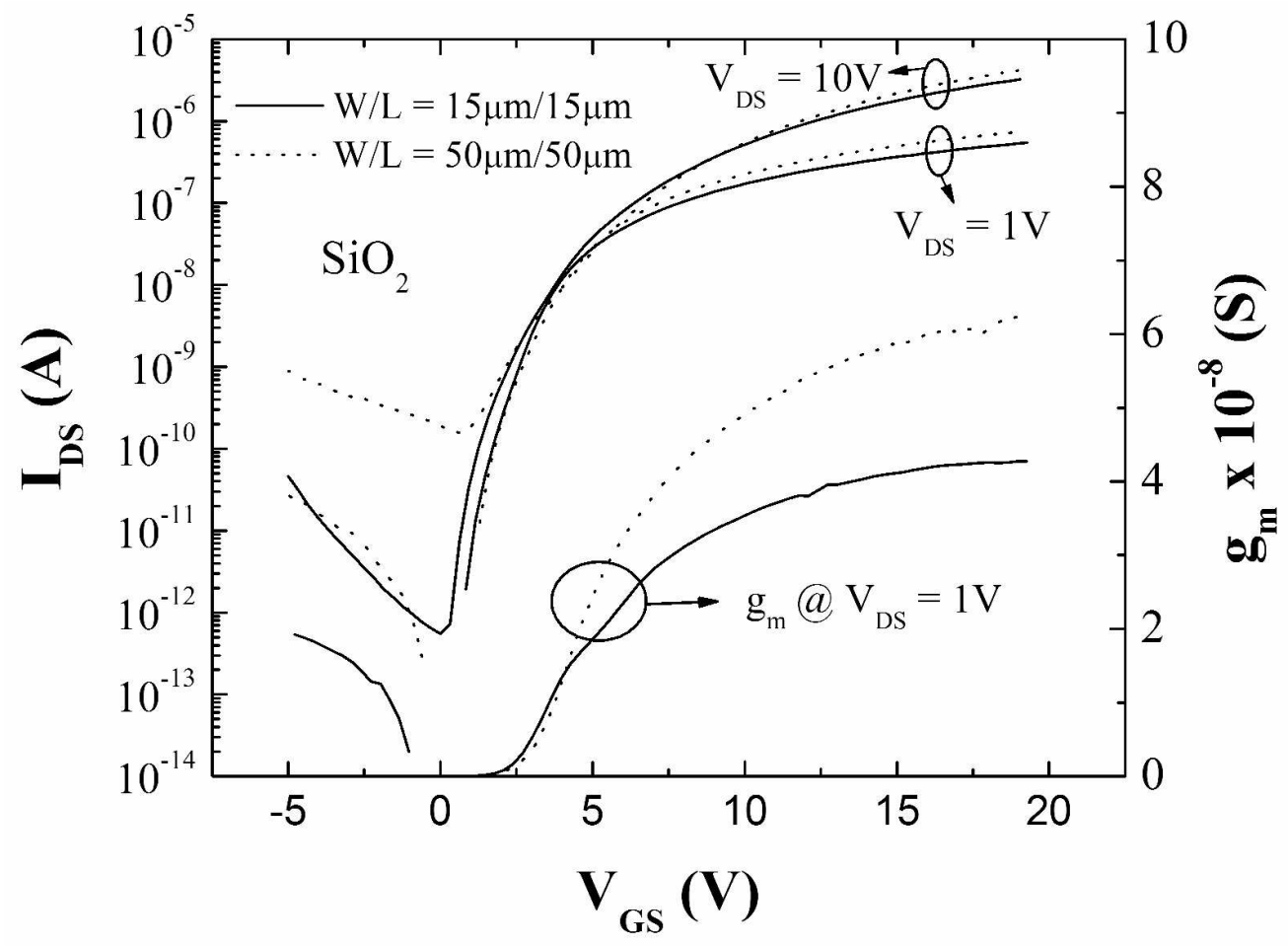

$269 \times 206 \mathrm{~mm}(300 \times 300 \mathrm{DPI})$ 


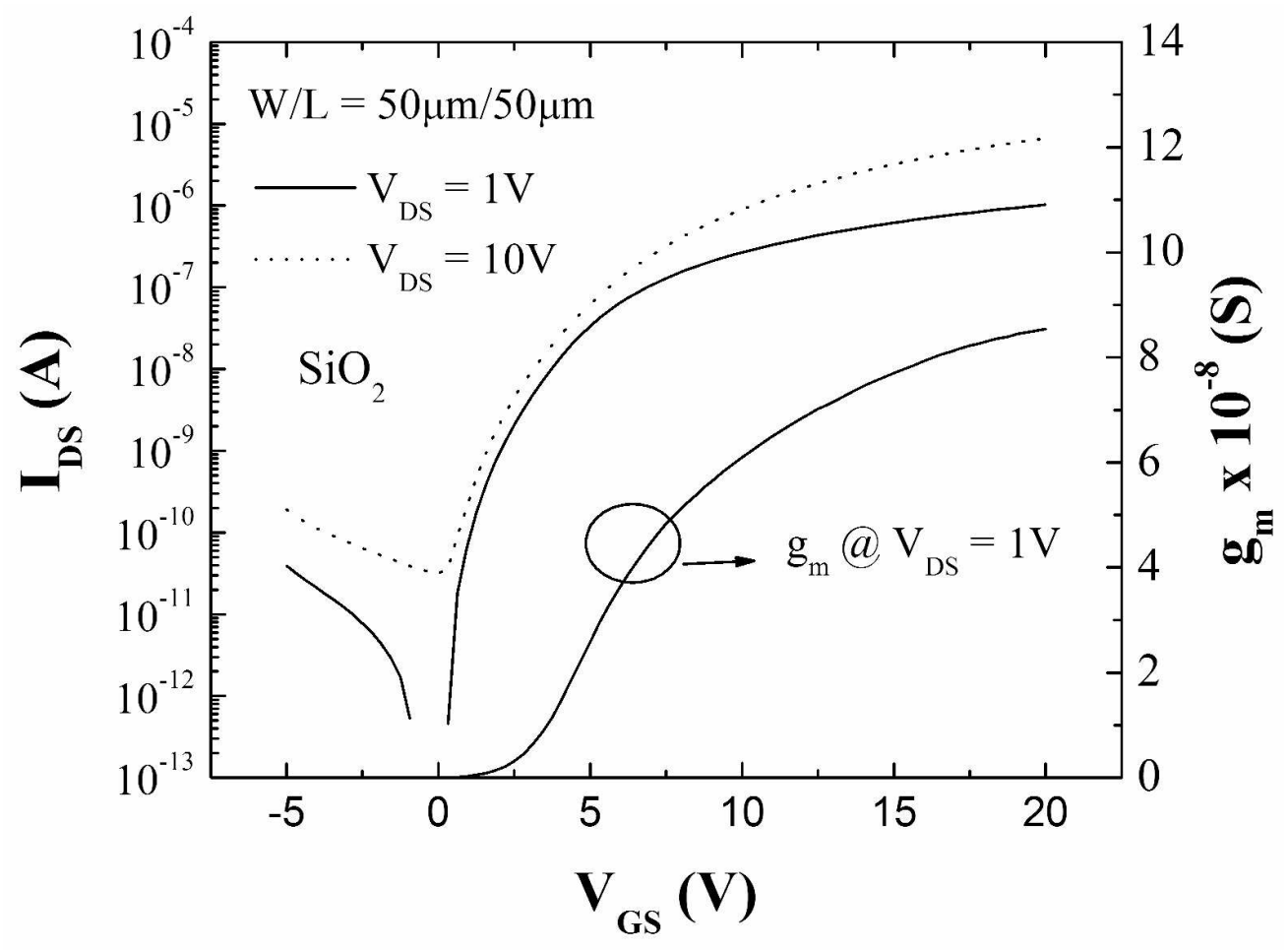

$269 \times 206 \mathrm{~mm}(300 \times 300$ DPI $)$ 


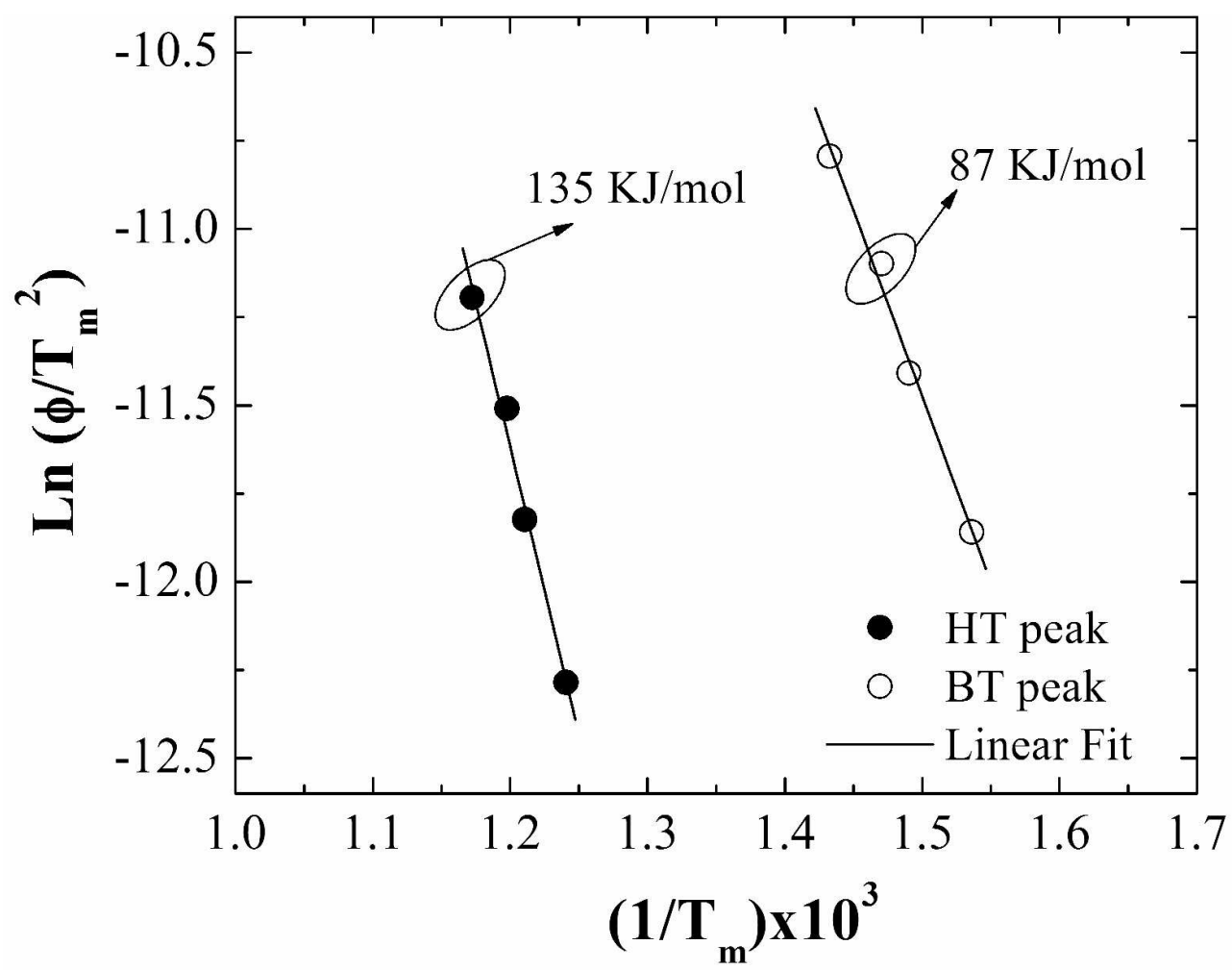

Figure 11. Activation energy for nanostructured films processed in the transition region. Data from Figure 8 were fitted by equation 2 . $269 \times 206 \mathrm{~mm}(300 \times 300$ DPI $)$ 


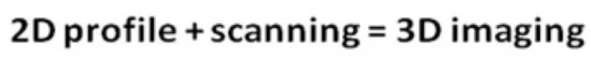

128 integrated psd

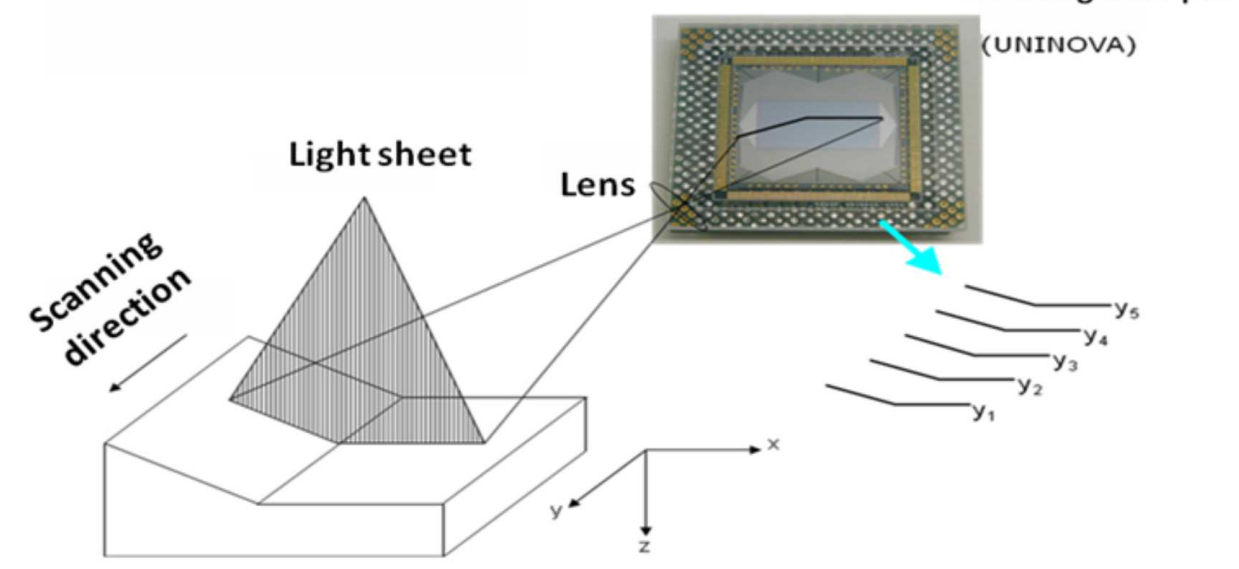

Figure 12. Schematic of the light line projected onto de integrated 128 psd arrays that contains the information of the object to be displayed. 


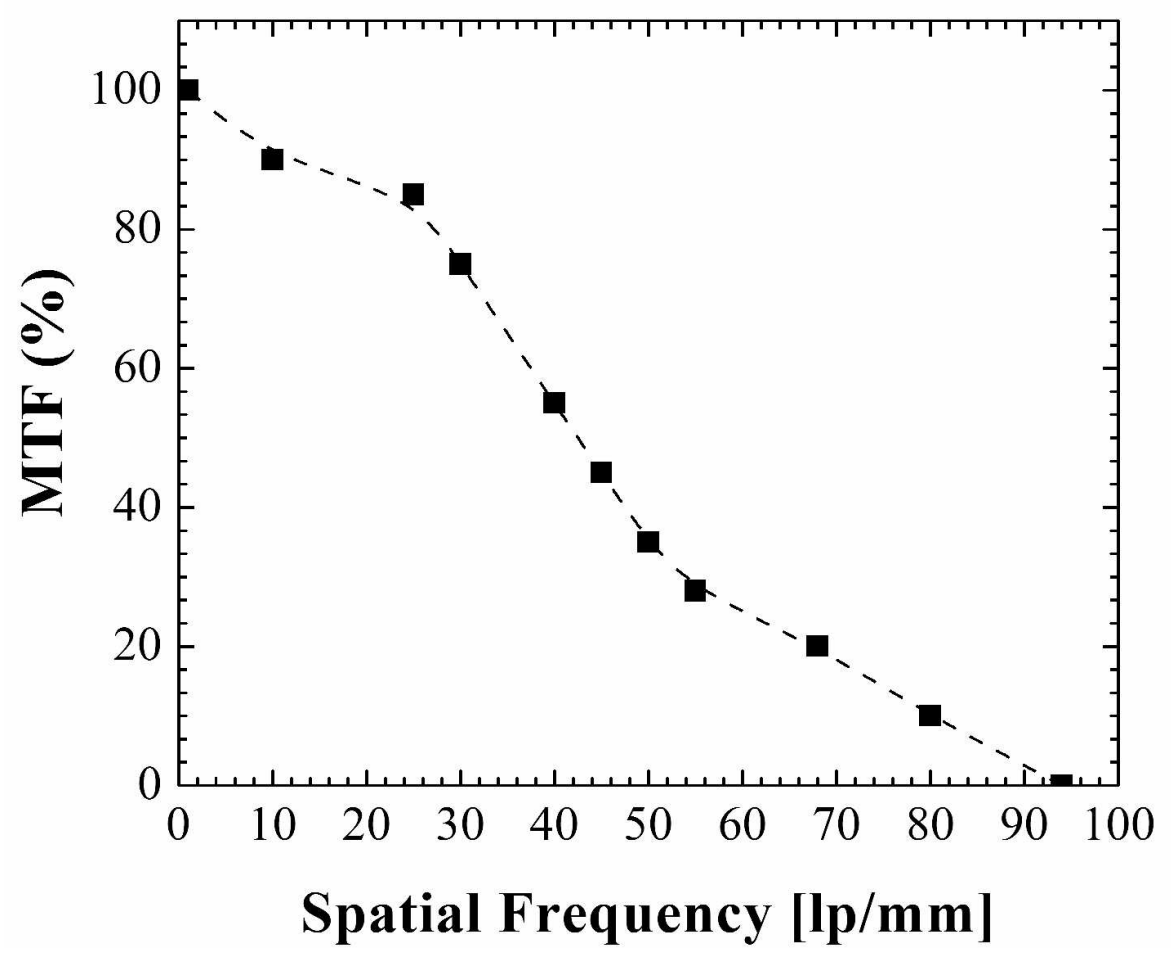

Figure 13. MTF (\%) as a function of the spatial frequency. $269 \times 207 \mathrm{~mm}(300 \times 300 \mathrm{DPI})$ 

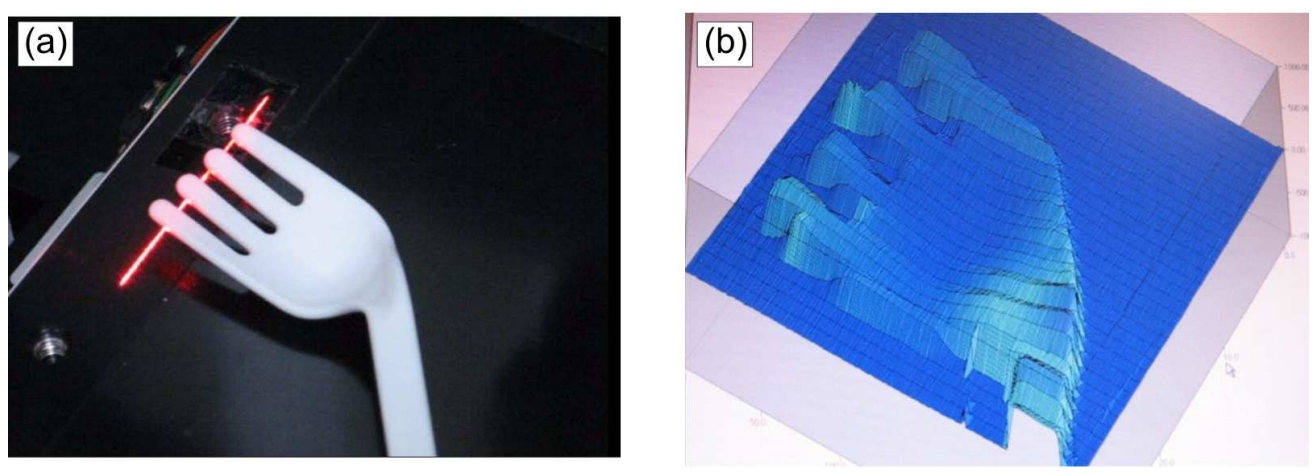

Figure 14. (a) Image to be 3D scanned, showing the laser line projected on it; (b) collected image by the sensor, in real time, without any type of data treatment. 